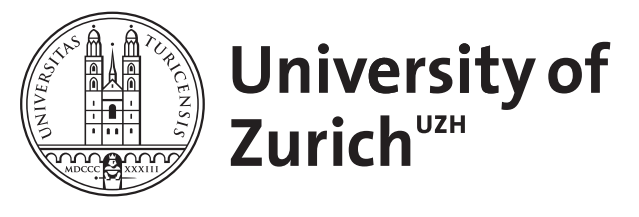

\title{
Money and liquidity in financial markets
}

\author{
Nyborg, Kjell G ; Östberg, Per
}

\begin{abstract}
We argue that there is a connection between the interbank market for liquidity and the broader financial markets, which has its basis in demand for liquidity by banks. Tightness in the market for liquidity leads banks to engage in what we term "liquidity pull-back," which involves selling financial assets either by banks directly or by levered investors. Empirical tests on the stock market are supportive. Tighter interbank markets are associated with relatively more volume in more liquid stocks; selling pressure, especially in more liquid stocks; and transitory negative returns. We control for market-wide uncertainty and in the process also contribute to the literature on portfolio rebalancing. Our general point is that money matters in financial markets.
\end{abstract}

DOI: https://doi.org/10.1016/j.jfineco.2013.12.003

Posted at the Zurich Open Repository and Archive, University of Zurich

ZORA URL: https://doi.org/10.5167/uzh-93848

Journal Article

Accepted Version

Originally published at:

Nyborg, Kjell G; Östberg, Per (2014). Money and liquidity in financial markets. Journal of Financial Economics, 112(1):30-52.

DOI: https://doi.org/10.1016/j.jfineco.2013.12.003 


\section{Money and Liquidity in Financial Markets ${ }^{1}$}

\author{
Kjell G. Nyborg \\ University of Zürich, \\ Swiss Finance Institute, \\ NHH and CEPR
}

\section{Per Östberg}

University of Zürich,

Swiss Finance Institute,

and $\mathrm{NHH}$

June 2010

First draft: November 2009

\footnotetext{
${ }^{1}$ We thank Zexi Wang for research assistance. We are also grateful for comments from seminar participants at the Bank of Finland, Copenhagen Business School, ESSEC, European Central Bank, ISCTE, Warwick Business School, and the Universities of Alabama, Gothenburg, South Carolina, and Zürich as well as from members of the external board of the Swiss Banking Institute and Henrik Hasseltoft.

Nyborg: Swiss Banking Institute, University of Zürich, Plattenstrasse 14, 8032 Zürich, Switzerland. Email: nyborg@isb.uzh.ch. Östberg: Swiss Banking Institute, University of Zürich, Plattenstrasse 14, 8032 Zürich, Switzerland.
} 


\section{Abstract \\ Money and Liquidity in Financial Markets}

We argue that there is a connection between the interbank market for liquidity and the broader financial markets, which has its basis in demand for liquidity by banks. Tightness in the interbank market for liquidity leads banks to engage in what we term "liquidity pull-back," which involves selling financial assets either by banks directly or by levered investors. Empirical tests support this hypothesis. While our data covers part of the recent crisis period, our results are not driven by the crisis. Our general point is that

money matters in financial markets. Different financial assets have different degrees of moneyness (liquidity) and, as a result, there are systematic cross-sectional variations in trading activity as the price of liquidity, or the level of tightness, in the interbank market fluctuates.

Keywords: money, liquidity, interbank and financial markets, liquidity pull-back JEL: G12, G21, E41, E44, E51 
- All the rivers run into the sea; yet the sea is not full: unto the place from whence the rivers come, thither they return again.

Ecclesiastes 1:7

\section{Introduction}

We study the connection between the interbank market for liquidity and the broader financial markets. That such a connection exists is suggested, for example, by the experience of the recent financial crisis, where we saw both a breakdown in the interbank market and a collapse in the prices of financial assets. There is also evidence in the extant literature that financial markets are affected by monetary phenomena. For example, returns in bond and equity markets appear to be influenced by monetary shocks (Fleming and Remolona 1997, Fair 2002, Piazzesi 2005) and fund flows (Edelen and Warner 2001, Boyer and Zheng 2009, Goetzmann and Massa 2002), as are measures of liquidity in these markets (Chordia, Sarkar, and Subrahmanyam, 2005). However, we are not aware of research that explicitly documents a link between the interbank market and the broader financial markets, as we do in this paper.

Our motivation for this line of inquiry has its basis in a money and banking perspective on financial market activity. Banks need liquidity, or central bank money, to satisfy reserve requirements, allow depositor withdrawals, etc. The central bank determines the quantity of liquidity via its operations and then the interbank market (re)allocates it. However, if the price of liquidity in the interbank market is high, alternative sources of liquidity may be more attractive. Banks that have exhausted credit limits, must look for alternative sources. But to paraphrase Friedman (1970), "One bank can increase its money balances only by persuading another one to decrease its balances." ${ }^{1}$ And as emphasized by Tobin (1980), "The nominal supply of money is something to which the economy must adapt,

\footnotetext{
${ }^{1}$ The original Friedman quote is: "One man can reduce his nominal money balances only by persuading someone else to increase his. The community as a whole cannot in general spend more than it receives."
} 
not a variable that adapts itself to the economy - unless the policy authorities want it to." So what alternatives to the interbank market are there?

Banks have, in fact, several alternatives. They can go to the discount window, but this is expensive and a last resort. They can try to induce more deposits, but this is unlikely to be effective within a short time span. Rather, the alternative that we wish to emphasize here, is selling financial assets and/or increasing margins to investors, which in turn may lead to asset sales as investors seek to meet margin requirements. ${ }^{2}$ This does not increase the quantity of liquidity in the system, but it can increase the selling bank's liquidity balances, as long as the buying counterparty banks with another bank. One can think of this as a kind of "liquidity pull-back," where a bank dips its ladle into the "ocean" of financial assets and recovers, for itself, liquidity granted to a counterparty some time in the past and stored all the while in the financial asset that now is being sold.

Thus, we argue that there is a connection between the interbank market for liquidity and the broader financial markets arising from (the possibility of) liquidity pull-back. There are two potential facets to this connection. First, a higher price of liquidity, ceteris paribus, should be associated with offsetting drops in asset prices. This is so as to equalize, insofar as possible, the cost of acquiring liquidity directly in the interbank market versus acquiring it indirectly by selling assets in the financial markets. The other facet of the connection relates to the volume of trade. This will be the main focus of our empirical analysis and to which we now turn.

Liquidity pull-back trading is arguably most likely to occur if the interbank market is not allocatively efficient. The crisis is an example of it being so; volume in the interbank market fell (Cassola, Holthausen, and Lo Duca, 2008) while central banks around the world injected vast amounts of liquidity to counteract banks' unwillingness to lend to each other. In addition, Bindseil, Nyborg, and Strebulaev (2009) find evidence that there is a degree of allocational inefficiency in the interbank market even during what we think of as times of normalcy, and Fecht, Nyborg, and Rocholl (2008) find evidence that interbank

\footnotetext{
${ }^{2}$ Kashyap and Stein (2000) document that many banks hold substantial amounts of securities.
} 
liquidity networks, which are intended to overcome imperfections in the interbank market, are not always effective.

Thus, we expect increased tightening in the interbank market to give rise to an increased volume of liquidity pull-back trading. To test this idea, we focus on the cross-sectional implications. In particular, the liquidity pull-back effect on volume should be felt differentially across assets, depending on their degree of liquidity in the financial economics sense of the word. By definition, trade in a highly liquid asset involves lower price impact, or transaction costs, on average than an equivalent trade in a less liquid asset (Black 1971, Kyle 1985). The implication, and our central hypothesis, is thus that increased tightness in the interbank market for liquidity is associated with an increase in the volume of more liquid assets relative to that of less liquid assets.

From the perspective advanced in this paper, selling a financial asset can be thought of as an act of converting low powered money (financial assets) into higher powered money (liquidity). When the price of liquidity goes up, the price of conversion also rises and asset prices therefore fall. However, with respect to this price effect, we expect no differential impact across assets of different liquidity levels, since in equilibrium there should be an equalization across assets of the marginal costs of converting into higher powered money.

We test these hypotheses on the CRSP universe of stocks using the three month LiborOIS and TED spreads as measures of tightness in the interbank market. ${ }^{3}$ The Libor-OIS spread may be a more precise measure of the state of the interbank market, since it is the difference between two interbank rates, rather than an interbank and a treasury rate. However, we have a longer time series of the TED spread. The in-sample correlation between the two spreads is .92 . While one might think that liquidity-pull back may be more prevalent in the Treasury security or broader fixed income markets, testing our hypotheses using the CRSP universe of stocks offers several advantages. First, the data is reliable and of high quality. Second, there are thousands of stocks, with a wide range of

\footnotetext{
${ }^{3}$ Libor is London Interbank Offered Rate, OIS is overnight index swap, TED spread is 3 month Libor less the 3 month treasury bill rate.
} 
liquidity levels. Third, there is homogeneity in trading infrastructure.

The empirical design involves forming portfolios of stocks based on the Amihud (2002) price impact measure of liquidity. Our predictions are confirmed in the data: First, the market share of volume of highly liquid stocks is increasing in either spread; second, the difference in portfolio returns between high and low spread days is negative, but the size of the difference does not depend on the degree of liquidity of the portfolio.

While we use it as a general measure of tightness in the interbank market, the LiborOIS spread can be viewed more specifically as a measure of the price of liquidity. A "Libor transaction" gives the borrower a fixed quantity of liquidity for a fixed period of time. The alternative (in the unsecured end of the market) is borrowing overnight and hedging the interest rate risk using the OIS. But this entails quantity risk; a bank cannot be sure that it will get the desired quantity of liquidity every day over the next three months, say. ${ }^{4}$ While the spread thus captures the extra cost of having the liquidity for sure, we believe it also reflects at least an element of the quantity constraints inherent in our concept of interbank market tightness. The drop in interbank activity during the crisis (especially at the longer end) supports this view. In addition, Gorton and Metrick (2009) find that high Libor-OIS spreads coincide with increased haircuts in repos. From a theoretical perspective, standard Akerlof (1970) adverse selection reasoning yields a positive relation between the price of liquidity and unsatiated demand. ${ }^{5}$ Thus, the Libor-OIS spread may be viewed as a general measure of interbank tightness as well as a specific measure of the price of liquidity.

The empirical analysis in this paper is motivated by the theoretical framework sketched above. A less bank-centric line of reasoning that is consistent with our findings is as follows: Higher spreads imply higher funding costs for investors, as banks pass on their own borrowing costs. As a result, stock prices fall. In turn, this leads to margin calls and

\footnotetext{
${ }^{4}$ There is also some interest rate risk, since a bank's overnight borrowing costs will not necessarily be equal to or perfectly correlated with the floating rate that inputs into the OIS contract, for example since overnight rates may vary across banks.

${ }^{5}$ Adverse selection may also lead to credit rationing along the lines of Jaffee and Russell (1976) or Stiglitz and Weiss (1981).
} 
portfolio rebalancing, as already described. This still implies a connection between the interbank market for liquidity and the broader financial markets, but the role of banks is deemphasized. Our perspective differs from that of Grossman and Miller (1988) and Brunnermeier and Pedersen (2009), where selling pressure originates in the asset market rather than the money market. Brunnermeier and Pedersen in particular emphasize how a liquidity event in the asset market can lead to dramatic falls in prices, as providers of funding liquidity may tighten margins too much if they are uninformed about the cause of the liquidity event. In our framework, a severe decline in stock prices could potentially be triggered by unrest in the interbank market, for example arising from extreme adverse selection in that market. Both of these perspectives may well be relevant for understanding the collapse in the stock markets during the crisis.

This paper is related to several other literatures. Liquidity pull-back trading is a potential explanation for the commonality in liquidity found by Chordia, Subrahmanyam, and Roll (2000), Hasbrouck and Seppi (2001), and Huberman and Halka (2001). We also contribute to the literature on trading volume (e.g. Ying 1966, Karpoff 1987, Lo and Wang 2000, Chordia, Huh, and Subrahmanyam 2007) by documenting that the Libor-OIS and TED spreads are associated with cross-sectional variations in volume.

The rest of this paper is organized as follows. Section 2 describes our data sources and section 3 provides descriptive statistics. Section 4 examines volume and returns on high and low spread days for different levels of illiquidity. Section 5 performs further regression analyses. Section 6 examines robustness to the set of sample firms, and section 7 concludes. 


\section{Data}

\section{$2.1 \quad$ Spreads}

In this paper, the Libor-OIS spread refers to the difference between 3 month USD Libor and the 3 month USD overnight index swap rate. ${ }^{6}$ Libor is collected daily over the period $2^{\text {nd }}$ January 1986 to $31^{\text {st }}$ December 2008. This yields a total of 5,817 Libor observations. The OIS data are also daily, but only cover the period from $4^{\text {th }}$ December 2001 to $11^{\text {th }}$ November 2008. Thus, we have 1,716 daily observations of the Libor-OIS spread.

The TED spread is defined as the difference between the 3 month USD Libor rate and the 3 month T-Bill rate. ${ }^{7}$ The T-Bill data is available for the entire period for which we have Libor data. But on some days we only have one or the other rate, for example because bank holidays in the U.K. may fall on different days than U.S. holidays. Thus, we have 5,648 daily observations of the TED spread.

\subsection{Volume and Returns}

The stock market data comes from the Center for Research in Security Prices (CRSP). We consider stocks that are listed on the NYSE, NASDAQ and AMEX over the period 1986 to 2008, with CRSP share codes 10 or 11. Thus, we exclude ADRs, closed-end funds, REITs, and shares of firms incorporated outside of the U.S. We also exclude financials by removing firms with Standard Industrial Classification (SIC) codes between 6000 and 6999. Stocks that meet any of the following criteria at any time within a given year are also removed for that year: the stock price exceeds $\$ 999$ or the firm changes ticker, cusip, or exchange. This leaves us with an average of 4,506 individual stocks per day. The change in exchange removal criterion is used to minimize the impact that any market microstructure changes might have on the stock. In a later section, we also examine the robustness of our findings by removing all NASDAQ stocks.

\footnotetext{
${ }^{6}$ Libor is downloaded from http://www.bbalibor.com. The OIS rate is obtained from Reuters.

${ }^{7}$ The T-Bill data is obtained from http://www.federalreserve.gov/releases/h15/data.htm.
} 


\section{Overview and Descriptive Statistics}

This section provides an overview of some of the key inputs to our subsequent analysis, namely the Libor-OIS and TED spreads, measures of liquidity

\subsection{Spreads: The Price of Liquidity}

Figure 1 displays the Libor-OIS spread (in basis points, bp) over the period 4 December 2001 to 11 November 2008. The red (shaded dark) section of the graph represent the recent financial crisis. ${ }^{8}$ Figure 2 superimposes the TED spread on Figure 1. The reactions of the two spreads to the subprime crisis are seen to be similar. They fluctuated at low levels until August 2007, when they simultaneously increased sharply. Pre-crisis there is a slight upward trend in the TED spread, while there is a slight downward trend in the Libor-OIS spread. The correlation between the two spreads is $92 \%$.

Figure 3 displays the TED spread from 1986 to 2008. Crises are indicated in red (dark shading). There are several of these, e.g., the crash in October 1987 (Black Monday), the invasion of Kuwait in August 1990, the Russian financial crisis and the collapse of Long Term Capital Management (LTCM) at the end of 1998. ${ }^{9}$ We see that the price of liquidity, as measured by the TED spread, is typically at elevated levels when there is significant uncertainty, such as during a war or a financial crisis.

Table 1 confirms that the spreads are statistically significantly higher during crises than during normal times. For the TED spread, the non-crisis versus crisis means are, respectively, $48.47 \mathrm{bp}$ and $105.37 \mathrm{bp}$. For the Libor-OIS spreads, they are $11.34 \mathrm{bp}$ and 67.37. Both spreads reached their peak on the $10^{\text {th }}$ of October 2008, when the TED and

\footnotetext{
${ }^{8}$ Figure 1 indicates the crisis as starting in February 2007, which is when the first public signs of problems started to emerge. See, for example, BBC News, "Timeline: Sub-prime losses" on http://news.bbc.co.uk/2/hi/business/7096845.stm. Many commentators identify the beginning of the crisis with the second week of August 2007, when the Libor-OIS spread more than doubled. The exact beginning of the crisis is not important for the purpose of this paper.

${ }^{9}$ See the notes for Figure 3 in the appendix for details.
} 
Libor-OIS spreads stood at $456.88 \mathrm{bp}$ and $366.33 \mathrm{bp}$, respectively. The extreme magnitude of these numbers can be seen from the fact that they are equivalent to an increase by a factor of 9 and 8 standard deviations relative to the respective unconditional means, or, in terms of raw numbers, by a factor of 8 and 14 times.

There appears to be an association between interbank tightness and asset prices. For example, the recent crisis saw not only high spreads, but also declining asset prices. From 1 August 2007 to 31 March 2009, the S\&P 500 fell by 46\% and, in local currency, the DAX, NIKKEI, and the FTSE 100 fell by 45\%, 52\%, and 37\%, respectively. The other major financial crisis in our sample is the stock market crash of October 1987 (Black Monday). Roll (1988) notes that 19 out of 23 markets declined by more than 20 percent that month. As illustrated in Figure 3, the TED spread also spiked at this time. In October 1987, the TED spread had an average value of $195.2 \mathrm{bp}$, as compared with average values for September and August of 96.8 and $81.8 \mathrm{bp}$, respectively. This coincidence of extreme tightness in the market for liquidity and extreme falls in stock prices is suggestive of there being a link between the markets for liquidity and stocks. More scientific evidence that the TED spread affects stock market returns is provided by Ferson and Harvey (1993).

Our focus in this paper, however, is on testing the liquidity pull-back hypothesis by examining the effect of tightness in the interbank market on cross-sectional variations in volume. The figures and summary statistics above illustrate that there is substantial time variation in the price of liquidity, either as measured by the Libor-OIS spread or the TED spread. While much of this variation is due to crisis periods, there is also a fair amount of variation during non-crisis times. The coefficient of variation during non-crisis times is 0.67 and 0.32 for the TED and Libor-OIS spread, respectively. Chordia, Roll and Subrahmanyam (2001) document that there are day of the week and holiday effects in aggregate dollar volume. However, as seen in Table 1, there are no such effects in the Libor-OIS and TED spreads. This is important because it means that our findings below which relate variations in these spreads to the relative volume of stocks with different levels of illiquidity are not driven by systematic day of the week effects. 


\subsection{Illiquidity}

To test the hypothesis that the volume of liquid and illiquid stocks respond differently to the price of liquidity we need a measure of the liquidity of stocks. Goyenko, Holden and Trczinka (2009) show that low-frequency measures of liquidity based on daily data perform well as compared with high frequency intraday measures. Low frequency measures have the advantage of being computable for a larger range of stocks over longer time horizons than measures based on intraday data. Among low frequency price impact measures, the best performer is Amihud's (2002) ILLIQ, which we therefore employ in this paper.

We measure $I L L I Q$ on a monthly basis. For stock $i$ and month $j, I L L I Q$ is defined as:

$$
\operatorname{ILLIQ} Q_{i j}=\text { Average }\left(\frac{\left|r_{t}\right|}{\text { Volume }_{t}}\right)
$$

where, $\left|r_{t}\right|$ and Volume $_{t}$ are the absolute value of the stock's rate of return and dollar volume, respectively, on day $t$. Thus, a large $I L L I Q$ is indicative of a highly illiquid stock, since price impact per unit of volume is large. The average in (1) is taken across observations for stock $i$ in month $j$ where recorded volume is positive. We exclude observations with no recorded closing price on either day $t$ or day $t-1$ and a zero return on day $t$, as this is highly suggestive of stale prices and spurious volume. ${ }^{10}$ This exclusion results in a loss of less than $2 \%$ of monthly ILLIQ observations.

Throughout the paper, we work with portfolios sorted by ILLIQ on a monthly basis. In particular, each month stocks are sorted into 10 groups based on their ILLIQ for that month. Group 1 consists of the month's 10\% most liquid stocks, i.e., the stocks with the lowest ILLIQ, Group 2 consists of the next $10 \%$ most liquid stocks, etc. Table 2 examines the month-to-month stability of the groups, by providing month-by-month transition frequencies from one group to another. Not surprisingly, the more liquid and illiquid groups

\footnotetext{
${ }^{10}$ In the CRSP database, all days without a recorded closing price are given a "closing" price of the bid/ask average and this situation is flagged by the use of negative numbers. There are occurrences in the database where there is no recorded closing price, thus suggesting an absence of trade, yet there is positive recorded volume.
} 
are more stable than the groups in the middle. For groups 1, 5, and 10, the proportion of stocks that remain in the group the next month is $89.88 \%, 48.46 \%$, and $72.90 \%$, respectively. In all of our analysis, for example when examining the impact of the Libor-OIS spread on volume across different liquidity groups, we work with liquidity groups based on the previous month's $I L L I Q \mathrm{~s}$.

Table 3, Panel A, provides descriptive statistics of individual stock's monthly ILLIQ. The pooled sample mean is 17.63 (median 0.134). By way of comparison, Goyenko et al. (2009) report a mean of 6.31 (median 0.104). ${ }^{11}$ Thus, the stocks in our sample are more illiquid than those in Goyenko et al.'s sample. Potential reasons for this difference include: (i) Goyenko et al. require their sample firms to be present in the TAQ master file (because of their objective to compare the performance of high and low frequency measures), which we do not. (ii) They consider the time period 1993 to 2005 while we consider 1986 to 2008. (iii) They consider a random sample of 400 firms, while we use the entire CRSP database. Both our and their estimates can be viewed as being large; a volume of 1 million dollars implies a price change of $13.4 \%$ for the median firm in our sample and $10.4 \%$ in Goyenko et al.'s sample. However, for the most part, we only use stocks' $I L L I Q$ values to classify them into groups. For our purposes, it is the ordinal, not cardinal, accuracy of $I L L I Q$ that matters. $^{12}$

Panel B provides descriptive statistics of the average ILLIQ within groups. There is substantial variation across groups. The average $I L L I Q$ is 0.001 for Group 1 and 162.601 for Group 10.

\footnotetext{
${ }^{11}$ These numbers refer to the plain (or raw) ILLIQ multiplied by $1,000,000$. That is to say, volume is measured in millions.

${ }^{12}$ If cardinal accuracy is important, it may be advisable to use an Acharya and Pedersen (2005) style truncation of $I L L I Q$ in order to reduce the impact of extreme observations. In this paper, this is an issue only for the regressions in Table 8. Footnote 16 discusses this further.
} 


\subsection{Volume and Returns}

Our analysis of volume in this paper revolves around four measures of normalized and relative volume.

1. For each stock or illiquidity group $i$ and day $t$, we calculate:

normalized share volume ${ }_{i, t}=\frac{\text { Volume }_{i, t}}{\text { Average volume for } i \text { over the previous five days }}$,

where volume is the number of shares traded.

2. normalized dollar volume it, $_{\text {. }}$

This is defined the same way as normalized share volume, but with volume now being the dollar value of trades. The two normalized volume measures capture abnormal volume on a given day in a simple way.

3. For each pair of illiquidity groups, $X$ and $Y$, we calculate their relative volume on day $t$ as:

Relative Volume of Group $X$ to Group $Y_{t}=\frac{\text { Volume Group } X_{t}}{\text { Volume Group } Y_{t}}$,

where volume is measured in dollars.

4. For each illiquidity group $G$, we calculate its market share of volume on day $t$ as: Market Share of Volume Group $G_{t}=\frac{\text { Volume Group } G_{t}}{\text { Aggregate volume } t \text { across all stocks in the sample }}$, where volume is measured in dollars.

To get a sense of the typical magnitudes of these variables, Panel $\mathrm{C}$ of Table 3 provides some summary statistics. First, for each day we calculate the normalized share volume for each individual stock and then take their equally weighted average, thus obtaining a series of daily observations of what we call the market normalized share volume. The market normalized dollar volume is calculated analogously. The averages of these two measures are 1.007 (share) and 1.009 (dollar). In other words, for a typical stock, share (dollar) 
volume increases by approximately $0.7 \%$ (0.9\%) per day. But there is significant variation over time. On one occasion, the market normalized share volume is 2.318, which translates into $231.8 \%$. This coincided with a value-weighted market return of $3.3 \%$ and occurred on 17 January 1991, which was close to the liberation of Kuwait. Market normalized share and dollar volumes reach their minimum values (a reduction in volume of roughly 70\%) around Christmas (24 $4^{\text {th }}$ and $26^{\text {th }}$ of December), Thanksgiving (end of November), and the $4^{\text {th }}$ of July.

Panel C also provides summary statistics for the relative volume of Group 10 to Group 1 , reported in per mille ${ }^{13}$. The daily mean is 0.43 per mille. The large fluctuation in the relative volume between these two extreme groups is illustrated by the range of 0.033 to 29.03 per mille. We also see that the mean Market Share of Volume for Group 1 is 78.6\%, with the range going from $56.4 \%$ to $91.5 \%$.

Finally, with respect to returns, the equally and value weighted daily market returns are $0.079 \%$ and $0.042 \%$, respectively. In terms of value weighted returns, the largest drop on a single day is $-17.135 \%$, which occurred on Black Monday, 19 October 1987. The largest daily gain is $11.518 \%$ (13 October of 2008).

\subsection{Correlations}

Table 4 presents correlations among the volume and return variables from Panel C, Table 3 as well as the Libor-OIS and TED spreads. We have also included two-day volume and return measures, e.g. the average market normalized share return over day $t$ and $t+1$ etc. The correlation structure has three noteworthy features.

First, the correlation between the spreads and market normalized share and dollar volume range from -0.02 to 0.02 . Thus, variations in the price of liquidity are not associated with abnormal volume in the market as a whole.

However (and second), it is associated with systematic variation in volume cross-

\footnotetext{
${ }^{13}$ In other words, the "raw" relative volume is multiplied by $10^{3}$.
} 
sectionally. The correlation between the Libor-OIS and TED spreads and the Relative Volume of Group 10 to Group 1 are -0.11 and -0.09, respectively. In other words, a higher price of liquidity coincides with relatively more trade in liquid stocks. This can also be seen from the positive correlation between the Market Share of Volume of Group 1 and the spreads.

Third, the correlation between the Libor-OIS spread and the contemporaneous equally and value weighted market returns are -0.17 and -0.13 , respectively. The correlations between the TED spread and market returns are also negative. This mirrors the observation above that the price of liquidity is often large when markets experience downturns.

These findings are in line with the theoretical framework laid out in the introduction and, in particular, with the predictions of the liquidity pull-back hypothesis. Below, we investigate the relation between the price of liquidity and the volume and returns of stocks with different liquidity levels in more detail.

\section{Volume and Return on High vs. Low Spread Days}

According to the liquidity pull-back hypothesis, the volume of highly liquid stocks relative to that of illiquid stocks goes up as the interbank market gets more tight. Prices are also predicted to fall for liquid stocks as well as for illiquid stocks, though not differentially so. To examine this, in this section we divide days of the month into high and low Libor-OIS and TED spread days. We then compare normalized share and dollar volumes as well as returns across liquidity groups on high versus low spread days. The idea is that if there is a liquidity pull-back effect, it should be visible on extreme spread days.

We proceed, separately for the Libor-OIS and TED spreads, as follows: For each month we: (i) select the two days with the highest and the two days with the lowest spreads; and (ii) average the values of the spread and any other variable that we are interested in, such as normalized share volume, on the two high as well as the two low spread days. In this way, for each variable of interest we generate two time series with monthly observations, 
corresponding to the variable's within-month average value on high and low spread days, respectively. ${ }^{14}$ Since each month in the sample period contributes equally to any statistic we calculate, this procedure controls for changes in the level of the spreads over time (e.g. crisis versus non-crisis periods).

Table 5 contains summary statistics of the monthly times series of the Libor-OIS and TED spreads on their respective monthly high and low days. These are significantly different, both in an economic and statistical sense. For the Libor-OIS spread, the average high and low days are $33.03 \mathrm{bp}$ and $21.69 \mathrm{bp}$. For the TED spread, they are $70.11 \mathrm{bp}$ and 43.14 bp. Over the period for which we have Libor-OIS spread data, the high and low TED spread series average to $62.31 \mathrm{bp}$ and $38.88 \mathrm{bp}$.

With respect to volume and return variables, we create separate series, on high and low spread days as described above, for all ten illiquidity groups. ${ }^{15}$ The variables we track are: normalized share volume, normalized dollar volume, the average of normalized share volume on day $t$ (the high or low spread day) and day $t+1$, the average of normalized dollar volume on day $t$ and day $t+1$, the equally weighted return across stocks in the group, and the equally weighted return across stocks in the group on day $t$ and $t+1$. The volume variables are calculated for the group as a whole (i.e. not averaged across the stocks in the group).

\footnotetext{
${ }^{14}$ For a given month and spread, if there are more than two highest spread days, then all of those days are weighted equally when calculating the monthly values of the variables we are looking at. If there is a single highest spread day but several second highest spread days, then the latter are weighted equally. For example, if four days have the second highest spread for a particular month then, for that month, each of these four days represent one fourth of a high spread day. For a given variable (e.g. normalized share volume), the monthly observation of the high spread day is then 0.5 times the variable's value on the unique high spread day plus 0.5 times the average value on the second highest spread days. We proceed in the analogous way for low spread days.

${ }^{15}$ The groups are formed a month in advance. That is, the volume and return variables are estimated using data from the current month, while groups are based on the previous month's ILLIQs.
} 


\subsection{Initial Results}

Table 6, Panel A, reports average values of the selected variables on high and low LiborOIS spread days for each illiquidity group. There is a marked difference in the behavior of the volume variables for liquid and illiquid stocks. For example, on low spread days, the most illiquid stocks (Group 10) have a normalized share (dollar) volume of 1.090 (1.154) versus 0.999 (1.006) for the most liquid stocks. Put differently, the most illiquid stocks have an abnormally large volume of $9 \%$ in terms of the number of shares traded on low spread days, while no effect is seen for the most liquid stocks. The difference is significant, both economically and statistically.

On high Libor-OIS spread days, the most liquid stocks experience an increase in share (dollar) volume of $5.8 \%(5.4 \%)$ relative to the average over the previous five days. The most illiquid stocks see a drop of $6.7 \%(7.8 \%)$. As reported in the table, a means test shows that the difference is statistically significant, having a t-statistic of 3.76 (2.95). Consistent with the liquidity pull-back hypothesis, this shows that volume is abnormally high (low) for highly liquid (illiquid) stocks on days when the price of liquidity is especially large.

In terms of returns, we see (not surprisingly) that illiquid stocks offer higher returns overall. More importantly with respect to the liquidity pull-back hypothesis, we also see that returns are uniformly smaller on high spread days.

Panel B reports on a similar exercise for the TED spread. The results parallel those for the Libor-OIS spread.

Table 7 reports on the differences in values between high and low spread days of the same volume and return variables as in Table 6. Panel A is based on the Libor-OIS and Panel B on the TED spread. Consistent with the liquidity pull-back hypothesis, for all four normalized volume measures and for each spread, the difference in volume between high and low spread days is decreasing in illiquidity, albeit not monotonically. For example, the differences in normalized share volume between high and low Libor-OIS spread days is $5.9 \%$ for Group 1 and $-15.7 \%$ for Group 10. Thus, as we go from low to high spread 
days, the abnormal volume for the most liquid stocks increases by a statistically significant $21.6 \%$ relative to that of the most illiquid stock. For the normalized dollar volume, the difference is even larger. These findings support the liquidity pull-back hypothesis.

Our theoretical framework also says that while returns should be lower on high spread days, the magnitude of the change should be similar for stocks with different liquidity levels. This is confirmed in Table 7. For each illiquidity group, returns are lower on high spread days. But in terms of the change in return from low to high spread days, there is no statistically significant difference between groups 1 and 10 . This is so whether we base our analysis on the Libor-OIS or the TED spreads.

These initial results support the view that high spreads are associated with an increase in volume for liquid stocks and a decrease for illiquid stocks. Our interpretation is that when the market for liquidity is tight, banks or investors choose to sell assets for which the price impact would be the least. That it is selling pressure that is behind the volume effect we have documented is corroborated by the negative returns on high spread days.

\subsection{Regression Analysis}

To further test the hypothesis that highly liquid (illiquid) stocks experience a relative increase (decrease) in volume as the interbank market gets increasingly tight, we run a Fama-MacBeth two step regression procedure as follows:

First, we run the following cross-sectional regression for each month, $m$ :

$$
H S V O L_{G, m}-L S V O L_{G, m}=\alpha_{m}+\beta_{m} \times I L L I Q_{G, m-1}+\varepsilon_{G, m}
$$

where $H S V O L_{G, m}-L S V O L_{G, m}$ is the difference in normalized share volume between high and low spread days in month $m$ for illiquidity group $G$, and $I L L I Q_{G, m-1}$ is the average $I L L I Q$ across stocks in the group in month $m-1$.

Second, we average the coefficients from the monthly regressions. These averages are reported in Table 8, with Newey-West (1987) (3 lags) t-statistics. 
This procedure is run separately for the Libor-OIS and TED spreads. And to examine robustness to the financial crisis, separate runs are done with and without the crisis. Consistent with our theoretical framework, the coefficient on $I L L I Q_{G}$ is negative regardless of which specification we look at. ${ }^{16}$ More specifically, the results are as follows:

Specification (1), TED spread: The coefficient on $I L L I Q_{G}$ is -0.0042 and is statistically significant at the $1 \%$ level. In terms of economic significance, going from the $25^{\text {th }}$ to $75^{\text {th }}$ percentile of $I L L I Q_{G}$ leads to a decrease in the difference in normalized share volume between high and low spread days of $0.78 \%$. This represents a reduction of $48.41 \%$ relative to the unconditional (pooled) mean difference in normalized share volume between low and high spread days. Using the TED spread over the Libor-OIS sample period [Specification (3)], reduces statistical significance slightly, but boosts economic impact: Going from the $25^{\text {th }}$ to $75^{\text {th }}$ percentile of $I L L I Q_{G}$ now reduces the difference in normalized share volume between high and low spread days of $59.75 \%$ relative to the unconditional mean.

Specification (2), Libor-OIS spread: The coefficient on $I L L I Q_{G}$ is -0.015 and is statistically significant at the $10 \%$ level. Going from the $25^{\text {th }}$ to $75^{\text {th }}$ percentile of $I L L I Q_{G}$ leads to a decrease in the difference in normalized share volume between high and low spread days of $30.53 \%$ relative to the unconditional mean.

Specification (4), TED spread, pre July 2007: The coefficient and t-statistic on $I L L I Q_{G}$ are almost identical to those in Specification (1).

Specification (5), Libor-OIS spread, pre July 2007: The coefficient on $I L L I Q_{G}$ is now -0.0168, which is slightly larger (in absolute value) as compared with the results when the full sample period is used [Specification (2)]. Surprisingly, statistical significance is very much improved - with the t-statistic going from -1.80 when the crisis is included to -2.79 without the crisis. This illustrates that the relation we have uncovered between changes in the price of liquidity and abnormal volume of highly liquid vs. illiquid stocks is not a

\footnotetext{
${ }^{16}$ We have also run the regressions in Table 8 using a truncated ILLIQ measure, along the lines of Acharya and Pedersen (2005), as follows: $I L L I Q_{i j, t r u n c}=\min \left(0.25+0.3 \times I L L I Q_{i j}, 30\right)$. This strengthens the results both in terms of statistical and economic significance.
} 
crisis phenomenon. Instead, that the state of the interbank market influences activity in the broader financial markets appears to be a fundamental and regular phenomenon.

In sum, the regression results in Table 8 confirm the findings in Tables 6 and 7 that an increase in the price of liquidity is associated with an increase in the volume of highly liquid stocks as compared to less liquid stocks. In a sense, our results in this section are even stronger than they would need to be to support the liquidity pull-back hypothesis. While the predictions are in terms of relative volume, our findings here show that the most liquid (illiquid) stocks have abnormally large (small) volume in an absolute sense on high spread days.

\section{Regression Analysis using Daily Observations}

The focus in this section is on regressions using the group-wise market share of volume and relative volume measures. These regressions rely on the ordinal, rather than the cardinal, accuracy of Amihud's ILLIQ measure. We use all days over the sample period, not just the extreme days from each month, as in the previous section. Thus, we examine whether an illiquidity group's relative volume is affected on a day to day basis by variations in the price of liquidity. According to the liquidity pull-back hypothesis, we expect a stronger negative association between market share of volume, or relative volume, and the price of liquidity for less liquid groups.

\subsection{Market Share of Volume}

For each group $G$, we run the following time series-regression using daily observations:

$$
\frac{\text { Market Share of Volume Group } G_{t}}{\text { mean }(\text { Market Share of Volume Group } G)}=\alpha+\beta \times \text { spread }_{t}+\varepsilon_{t}
$$

where $\operatorname{spread}_{t}$ is either the Libor-OIS or TED spread on date $t$ and, as always, illiquidity groups are formed based on individual stocks' ILLIQ values the previous month. We 
run separate regressions for each spread. To correct for autocorrelation, the regressions are run using the Cochrane-Orcutt procedure. ${ }^{17}$ So as to facilitate comparisons across illiquidity groups, we have normalized the market share of volume for each group by its time series average. Thus, we expect to see the slope coefficient to be inversely related to the group number. We expect a positive regression coefficient for the group consisting of the most liquid stocks (group number 1) and a negative coefficient for the most illiquid stocks (number 10).

Table 9, Panel A, displays the results using the TED spread. The coefficient on the spread is positive for the most liquid group (number 1) and negative for all other groups. All coefficients are statistically significant at the $1 \%$ level. In addition, the coefficient on the spread is decreasing (almost monotonically) in the illiquidity ranking of the groups. It is fair to say that these results are consistent with our hypothesis.

In terms of economic significance, a one standard deviation increase in the TED spread leads to an increase in the Market Share of Volume of Group 1 of $0.93 \%$ relative to the group's unconditional mean. For illiquidity group 10, a one standard deviation increase in the TED spread leads to a fall in the Market Share of Volume of Group 10 of $11.73 \%$ relative to this group's unconditional mean.

Panel B uses the Libor-OIS spread. The qualitative results are the same as for the TED spread. Statistical significance is slightly lower, but economic impact is generally larger for the Libor-OIS spread. For example, a one standard deviation increase in the Libor-OIS leads to an increase (decrease) in the Market Share of Volume of Group 1 (Group 10) of

\footnotetext{
${ }^{17}$ We have also run OLS regressions with Newey-West (5 lags) standard errors. In the majority of cases, this yields smaller standard errors and results that are more supportive of our hypothesis than the results using the Cochrane-Orcutt procedure that we report in Table 9. We have also run unit root tests on the Libor-OIS and TED spreads. Using the Augmented Dickey-Fuller test we reject that the Libor-OIS is a unit root at the $5 \%$ and that the TED spread is a unit root at the $1 \%$ level. We also reject that the Libor-OIS and TED spreads follows a unit root at the $1 \%$ level with the Zivot-Andrews (1992) test that allows for a structural break. This tests identifies a structural break in August 2007, which is also when visual inspection reveals a sharp increase in this spread. Details are available upon request.
} 
$1.11 \%(28.35 \%)$ relative to the group's unconditional mean.

Panel C uses the TED spread over the shorter period for which we have data on the Libor-OIS spread. The coefficients exhibit the same pattern as in the previous two panels, but statistical significance is spotty. That the TED spread works less well over the shorter Libor-OIS period may reflect that the TED spread is a noisy measure of the price of liquidity. However, the overall conclusion from Table 9 is that the volume of the most liquid stocks relative to the volume of the market as whole is increasing in the price of liquidity, as predicted by the liquidity pull-back hypothesis.

\subsection{Relative Volume}

Here, we look at the relative volume of illiquid to liquid stocks more directly by studying the Relative Volume of Group $X$ to Group $Y$ variable. Paralleling the market share of volume regressions in the previous section, the relative volume variable is normalized by its time-series mean so as to facilitate comparison across different pairs of groups. For any pair of groups, with $X>Y$ (i.e. group $X$ is the more illiquid), we estimate the following daily time-series regression,

$$
\frac{\text { Relative Volume of Group X to Group } Y_{t}}{\text { mean (Relative Volume of Group X to Group } Y)}=\alpha+\beta \times \operatorname{spread}_{t}+\varepsilon_{t}
$$

This makes a total of 45 regressions for each spread measure. All are run using the Cochrane-Orcutt procedure. ${ }^{18}$

Table 10, Panel A, reports on the 45 TED spread regressions. For each regression, we list the coefficient on the spread and its t-statistics (in brackets). 20 of the 45 coefficients are significantly negative. There is no instance in which a positive coefficient is statistically significant. There is a relatively large degree of insignificance for adjacent groups, especially among less liquid groups. However, in the regressions where Group 1 (most liquid stocks)

\footnotetext{
${ }^{18}$ We have also run OLS regressions with Newey-West (5 lags) standard errors. In the majority of cases, this yields smaller standard errors and results that are more supportive of our hypothesis than the results using the Cochrane-Orcutt procedure that we report in Table 10. Details are available upon request.
} 
is in the denominator, all regression coefficients are significantly negative. Moreover, the trend is for the coefficient to become increasingly negative as the group in the numerator becomes more illiquid. These results are in line with the liquidity pull-back hypothesis - relatively less liquidity is pulled back from less liquid stocks as the price of liquidity increases.

Economic impact is the largest for the regression involving the most extreme groups, namely numbers 10 and 1 . In this case, a one standard deviation increase in the TED spread reduces the relative volume by $13.37 \%$ as compared to the unconditional mean. For all other ratios, the impact is below $10 \%$ of the unconditional mean. However, when the denominator is either the volume of group 1 or group 2 (row 1 and 2 in the table) the impacts are always above $3 \%$ relative to the unconditional mean.

Panel B reports on the same regressions using the Libor-OIS spread. We observe the same pattern as for the TED spread, but the results are stronger. The coefficient on the spread is now significantly negative in 39 out of 45 cases. With respect to economic significance, a one standard deviation increase in the Libor-OIS spread now reduces the Relative Volume of Group 10 to Group 1 by $28.75 \%$ relative to the unconditional mean. The smallest such impact when Group 10 is in the numerator is $14.75 \%$.

Panel $\mathrm{C}$ uses the TED spread over the Libor-OIS period. The results are weaker than for the Libor-OIS spread itself. 20 out of 45 coefficients are significantly negative and economic impact is generally reduced. These weaker results parallel our findings when using the TED spread in the market share of volume regressions over the Libor-OIS period in the previous subsection. Overall, are findings are supportive of the liquidity pull-back hypothesis and that the Libor-OIS spread is a more accurate measure of tightness in the interbank market than the TED spread. 


\subsection{Panel Regressions: Normalized Share Volume}

We estimate panel regressions at the individual stock level using the normalized share volume as the dependent variable. We run two specifications (for each spread measure). Specification (1) is:

$$
\begin{aligned}
& {\text { Normalized Share } \text { Volume }_{i t}}= \\
& \alpha+\beta_{1} \times \text { spread }_{t} \times \text { Group }_{1, i t}+\ldots+\beta_{10} \times \text { spread }_{t} \times \text { Group }_{10, i t}+\varepsilon_{i t}
\end{aligned}
$$

where $\operatorname{Group}_{G, i t}$ is a dummy variable that takes the value 1 if stock $i$ belongs to illiquidity group $G$ at date $t$ and 0 otherwise. ${ }^{19}$ These are interacted with the spread, which as always is either the Libor-OIS or TED spread. Group dummies allow us to examine the effect of spreads on stocks with different levels of illiquidity without relying on the cardinal accuracy of ILLIQ for individual stocks. Standard errors are clustered daily in all regressions. To reduce the effect of outliers we remove observations where the normalized share volume is larger than 5. In specification (2), we include the market normalized share volume on day $t$ as a control variable.

If the liquidity pull-back hypothesis holds, we should see a decreasing coefficient on the group dummy $\times$ spread interaction variable as the group number increases (stocks become more illiquid). However, two factors makes it potentially more difficult to see significance in these regressions. First, the regressions are potentially more noisy because they are run on a stock by stock basis rather than on a portfolio basis. Second, the normalized share volume is strictly speaking a measure of abnormal volume for a given stock, rather than a direct measure of relative volume.

Table 11, Panel A, reports on the regressions with the TED spread. The results for specifications (1) and (2) are almost identical. The spread $\times$ group dummy is significantly positive (at the 1\% level) for groups 1 through 6 and significantly negative (at the $1 \%$ level) for groups 8 through 10. Moreover, the coefficient is declining in the group number (as stocks become more illiquid). This is as predicted by our hypothesis. The coefficient

\footnotetext{
${ }^{19}$ As always, groups are formed the previous calendar month.
} 
on Group 7 is insignificant, indicating that this is the marginal group.

The economic impacts are large. For Group 1, a one standard deviation increase in the TED spread leads to an increase in normalized share volume of $4.18 \%$ relative to the unconditional mean. For Group 10 a one standard deviation increase in the TED spread leads to a decrease in volume of $9.77 \%$ which represents a $9.70 \%$ decrease relative to the unconditional mean.

Panel B reports on the results using the Libor-OIS spread. The pattern of the results is broadly the same as for the TED spread, with the more liquid groups (lower numbered groups) having positive spread $\times$ group coefficients and the more illiquid groups having negative coefficients. Statistical significance is strong under specification (1), but weak, except for the most illiquid groups, under specification (2). With respect to economic significance, under specification (1) a one standard deviation increase in the Libor-OIS spread leads to an increase in the normalized share volume of stocks in Group 1 by $0.99 \%$, while for Group 10 stocks normalized share volume falls by $5.40 \%$ relative to their unconditional means.

Panel C uses the TED spread over the Libor-OIS period. The results are slightly stronger than for the Libor-OIS spread, especially for specification (2).

All in all, the findings in this subsection support the overall message of this paper that the price of liquidity affects volume differentially across stocks. In particular, whether we use the TED or the Libor-OIS spread to measure the price of liquidity, we always get the same result: an increase in the price of liquidity is associated with an increase in volume of liquid stocks, both relative to their own recent volume history and relative to less liquid stocks. The reverse holds for illiquid stocks.

\section{Robustness}

We have found that an increase in the Libor-OIS or TED spreads are associated with an increase in the relative volume of liquid stocks. To maximize the variation in liquidity across stocks, and thus hopefully the power of our tests, we have included stocks listed on 
all the major exchanges, NYSE, AMEX and NASDAQ. Sixtythree percent of our sample is comprised of NASDAQ stocks. However, as noted by Atkins and Dyl (1997) and Anderson and Dyl (2007), the volume of a stock that switches from NASDAQ to NYSE or AMEX often falls. This is due to the dealer structure on NASDAQ which implies a significant amount of transactions between dealers that is recorded as trading volume.

Could this NASDAQ volume inflation effect drive our results? For it do so, the distortion in our volume measures for NASDAQ stocks would have to covary with the Libor-OIS and TED spreads. For example, if NASDAQ stocks are less liquid, then on high spread days we would have to see a lower NASDAQ volume inflation than on low spread days.

To see whether our results are driven by the NASDAQ volume inflation effect, we remove all NASDAQ stocks from our dataset and redo our analysis on the reduced sample. We focus on the relative volume regressions, as in Table 10, since these arguably represent the most direct test of the liquidity pull-back hypothesis. For the sake of brevity, we only report the results when using the most liquid group (number 1) in the denominator of the relative volume measure. The regression coefficients on the spread (which here is the Libor-OIS spread) and the corresponding t-statistics are as follows:

\begin{tabular}{|llllllllll|}
\hline Numerator group: & 2 & 3 & 4 & 5 & 6 & 7 & 8 & 9 & 10 \\
\hline Spread coefficient: & -0.059 & -0.076 & -0.070 & -0.152 & -0.251 & -0.247 & -0.160 & -0.170 & -0.176 \\
t-statistic & $(-3.16)$ & $(-2.06)$ & $(-1.32)$ & $(-2.17)$ & $(-2.54)$ & $(-2.38)$ & $(-2.17)$ & $(-3.57)$ & $(-2.29)$ \\
\hline
\end{tabular}

These results are qualitatively very similar to those for the corresponding regressions in Table 10. For all regressions, the coefficient on the Libor-OIS spread is negative and, with one exception, statistically significant. Moreover, the coefficients are increasingly negative as the group number in the numerator increases (i.e. the group becomes increasingly illiquid). In terms of economic impact, a one standard deviation increase in the Libor-OIS spread now results in a drop in the Relative Volume of Group 10 to Group 1 of $12.4 \%$ as compared to the unconditional mean. Thus, the results are strong in terms of economic impact as well. In conclusion, our results are robust to the exclusion of NASDAQ stocks. 


\section{Conclusion}

We have argued that there is a connection between the interbank market for liquidity and the broader financial markets, which has its basis in demand for liquidity by banks. Tightness in the interbank market for liquidity leads banks to engage in what we term liquidity pull-back, which involves selling financial assets either by banks directly or by levered investors. Liquidity pull-back can be thought of as involving the conversion of low powered money (financial assets) into higher powered money. This does not increase the stock of money in aggregate, but can increase the money balances of an individual bank. This line of reasoning has several implications, and the body of the paper is devoted to testing these. The implications are verified in the data.

In our empirical analysis, we measure the state of the interbank market by the LiborOIS and TED spreads and the broader financial markets are represented by the equity markets. The main focus of our tests is on volume. Consistent with the liquidity pull-back hypothesis, the broad finding is that higher Libor-OIS and TED spreads are associated with an increase in the volume of highly liquid stocks and a decline in that of highly illiquid stocks. This pops out of the data regardless of how we perform our tests. We have tried four different approaches. To reduce noise, all are based on grouping stocks into 10 liquidity ordered portfolios. For the most part, our tests do not depend on the accuracy of the absolute measure of liquidity, but on the relative ranking induced by the measure.

First, we document that the volume of a portfolio, normalized by its own volume over the last 5 trading days, on high spread days relative to low spread days is increasing in the degree of liquidity of the portfolio. An equal number of high and low spread days are chosen across months, to control for time effects. Thus, the crisis does not contribute more high spread days than a non-crisis period of the same duration. The result is also explicitly shown to be robust to excluding the recent crisis.

Second, for each trading day, we calculate the volume of a portfolio as a percentage of total market volume, which we term the portfolio's market share of volume, and regress 
this on either spread. In the regressions, we normalize each portfolio's market share of volume on a given day by its own sample mean so that we can compare the "volume spread betas" of different portfolios in a meaningful way. The volume spread beta is statistically significantly positive for the most liquid portfolio and negative for all other portfolios. More illiquid portfolios have larger negative volume spread betas, i.e., the market share of volume declines faster for more illiquid portfolios as the spreads rise.

Third, for each trading day, we calculate the volume of a portfolio relative to that of a more liquid portfolio and regress this on either spread. In the regressions, we normalize each portfolio's relative volume on a given day by the respective sample mean. The general finding across these 45 relative volume regressions is that the relative volumes of less liquid portfolios are decreasing in either spread. This corroborates the results from the market share of volume regressions.

Fourth, we calculate the same normalized volume measure as in the first approach, but now on an individual stock level and for each trading day, not just high or low spread days. We then regress these normalized volume measures, in a panel, on either spread interacted with portfolio dummies, to control for the liquidity of the stock. Thus, we calculate spread betas for the different portfolios, but now using an individual stock's volume relative to the 5 preceding days as the independent variable. The panel structure allows us to take into account cross-correlation in regression errors on the same day across different stocks. This could occur, for example, if volume is particularly large or small across stocks on a given day for reasons that are exogenous to our model. Once again, we find that spread betas decrease in liquidity.

In addition to our finding on volume, we also document that across liquidity portfolios, returns are decreasing on high spread days. However, the difference in return between high and low spread days does not vary significantly across liquidity groups. This supports the view that the marginal cost of converting financial assets to higher powered money is equalized across assets.

The framework for thinking about money and liquidity in financial markets that we 
have outlined in this paper may be useful for understanding a number of liquidity phenomena. As an example, consider the phenomenon of increased correlations during crisis times (King and Wadhwani, 1990) and "flight to quality" (Sundaresan, 2009 p. 343). The recent crisis supports this; nearly all major stock indices such as the S\&P 500, the DAX, the FTSE 100, and the NIKKEI fell around 40\% to 50\% in local currency in the August 2007 to March 2009 period. The liquidity pull-back interpretation of the flight to quality phenomenon is that times when this happens are times when liquidity is extremely dear or difficult to get in the interbank market. Banks therefore engage in liquidity pull-back. Put differently, there is a (financial market) credit contraction. The conjecture is that the worse conditions are in the interbank market, the larger are asset cross-correlations and the stronger will flight to quality appear to be. We have presented some cursory evidence on asset returns. Investigating this more thoroughly is an important avenue for future research. 


\section{References}

[1] Acharya, Viral and Lasse H. Pedersen, 2005, Asset pricing with liquidity risk, Journal of Financial Economics 77, 375-410.

[2] Akerlof, George, A., 1970, The market for 'lemons': Quality uncertainty and the market mechanism, Quarterly Journal of Economics 84, 488-500.

[3] Amihud, Yakov, 2002, Illiquidity and stock returns: Cross section and time-series effects, Journal of Financial Markets 5, 31-56.

[4] Anderson, Anne M., and Edward A. Dyl, 2007, Trading Volume: NASDAQ and the NYSE, Financial Analysts Journal 63, 115-131.

[5] Atkins, Allen and Edward A. Dyl, 1997, Market Structure and Reported Trading Volume: Nasdaq versus the NYSE, Journal of Financial Research 20, 291-304.

[6] Bindseil, Ulrich, Kjell G. Nyborg and Ilya Strebulaev, 2009, Repo auctions and the market for liquidity, Journal of Money Credit and Banking 41, 1391-1421.

[7] Black, Fischer, 1971, Towards a fully automated exchange, Part I, Financial Analysts Journal 27, 29-34.

[8] Boyer, Brian and Lu Zheng, 2009, Investor flows and stock market returns, Journal of Empirical Finance 16, 87-100.

[9] Brunnermeier, Markus, K., and Lasse H. Pedersen, 2009, Market liquidity and funding liquidity, Review of Financial Studies 22, 2201-2238.

[10] Cassola, Nuno, Cornelia Holthausen, and Marco Lo Duca, 2008, The 2007/2008 turmoil: a challenge for the integration of the euro area money market?, European Central Bank Working Paper.

[11] Chordia, Tarun, Sahn-Wook Huh, and Avanidhar Subrahmanyam, 2007, The crosssection of expected trading activity, Review of Financial Studies 20, 709-740. 
[12] Chordia, Tarun, Richard Roll, and Avanidhar Subrahmanyam, 2000, Commonality in liquidity, Journal of Financial Economics 56, 3-28.

[13] Chordia, Tarun, Richard Roll, and Avanidhar Subrahmanyam, 2001, Market liquidity and trading activity, Journal of Finance 56, 501-530.

[14] Chordia, Tarun, Asani Sarkar, and Avanidhar Subrahmanyam, 2005, An empirical analysis of stocks and bond market liquidity, Review of Financial Studies 18, 85-130.

[15] Edelen, Roger, M., and Jerold B. Warner, 2001, Aggregate price effects of institutional trading: A study of mutual fund flow and market returns, Journal of Financial Economics 59, 195-220.

[16] Fair, Ray, C., 2002, Events that shock the market, Journal of Business 75, 713-731.

[17] Fecht, Falko, Kjell G. Nyborg, and Jörg Rocholl, 2008, The price of liquidity: Bank characteristics and market conditions, Deutsche Bundesbank, Discussion Paper Series 1: Economic Studies, no 2008/30.

[18] Ferson, Wayne E. and Campbell R. Harvey, 1993, The risk and predictability of international equity returns, Review of Financial Studies 6, 527-566.

[19] Fleming, Michael, J., and Eli M. Remolona, 1997, What moves the bond market?, FRBNY Economic Policy Review 3, 31-50.

[20] Friedman, Milton, 1970, A framework for monetary analysis, Journal of Political Economy 78, 193-238.

[21] Goetzmann, William, N., and Massimo Massa, 2002, Daily momentum and contrarian behavior of index fund investors, Journal of Financial and Quantitative Analysis 37, 375-389.

[22] Goyenko, Ruslan, Craig W. Holden, and Charles Trzcinka, 2009, Do liquidity measures measure liquidity? Journal of Financial Economics 92, 153-181. 
[23] Gorton, Gary, B., and Andrew Metrick, 2009, Securitized banking and the run on repo, Yale ICF Working Paper 09-14.

[24] Grossman, Sanford, J., and Merton Miller, 1988, Liquidity and market structure, Journal of Finance 43, 617-637.

[25] Hasbrouck, Joel, and Duane J. Seppi, 2001, Common Factors in Prices, Order Flow, and Liquidity, Journal of Financial Economics 59, 383-411.

[26] Huberman, Gur, and Dominika Halka, 2001, Systematic liquidity, Journal of Financial Research 24, 161-178.

[27] Jaffee, Dwight, M., and Thomas Russell, 1976, Imperfect information, uncertainty, and credit rationing, Quarterly Journal of Economics 90, 651-666.

[28] Kashyap, Anil, and Jeremy C. Stein, 2000, What do a million observations on banks say about the transmission of monetary policy?, American Economic Review 90, 407428.

[29] Karpoff, Jonathan, M., 1987, The relation between price changes and trading volume: A survey, Journal of Financial and Quantitative Analysis 22, 109-126.

[30] King, Mervyn, A., and Sushil Wadhwani, 1990, Transmission of volatility between stock markets, Review of Financial Studies 3, 5-33.

[31] Kyle, Albert, 1985, Continuous auctions and insider trading, Econometrica 53, 13151335.

[32] Lo, Andrew, W., and Jiang Wang, 2000, Trading volume: Definitions, data analysis, and implications of portfolio theory, Review of Financial Studies 13, 257-300.

[33] Newey, Whitney K., and Kenneth D. West, 1987, A Simple, Positive Semi-definite, Heteroskedasticity and Autocorrelation Consistent Covariance Matrix, Econometrica $55,703-708$. 
[34] Piazzezi, Monika, 2005, Bond yields and the Federal Reserve, Journal of Political Economy 113, 311-344.

[35] Roll, Richard, 1988, The international crash of october 1987, Financial Analysts Journal 19-35.

[36] Stiglitz, Joseph, E., and Andrew Weiss, 1981, Credit rationing in markets with imperfect information, American Economic Review 71, 393-410.

[37] Sundaresan, Suresh, 2009, Fixed income markets and their derivatives, Academic Press.

[38] Tobin, James, 1980, Redefining the aggregates: Comments on the exercise, in Measuring the Money Aggregates: Compendium of views prepared by the subcommittee on domestic monetary policy of the House committee on banking, finance, and urban affairs, 96th Congress, 2nd Session, Washington DC: US Government Printing Office.

[39] Ying, Charles, C., 1966, Stock market prices and volumes of sales, Econometrica 34, 676-685.

[40] Zivot, Eric and Donald W. K. Andrews, 1992, Further Evidence on the Great Crash, the Oil Price Shock and the Unit Root Hypothesis, Journal of Business and Economic Statistics 10, 251-270. 
Figure 1: The Libor-OIS spread (in basis points)

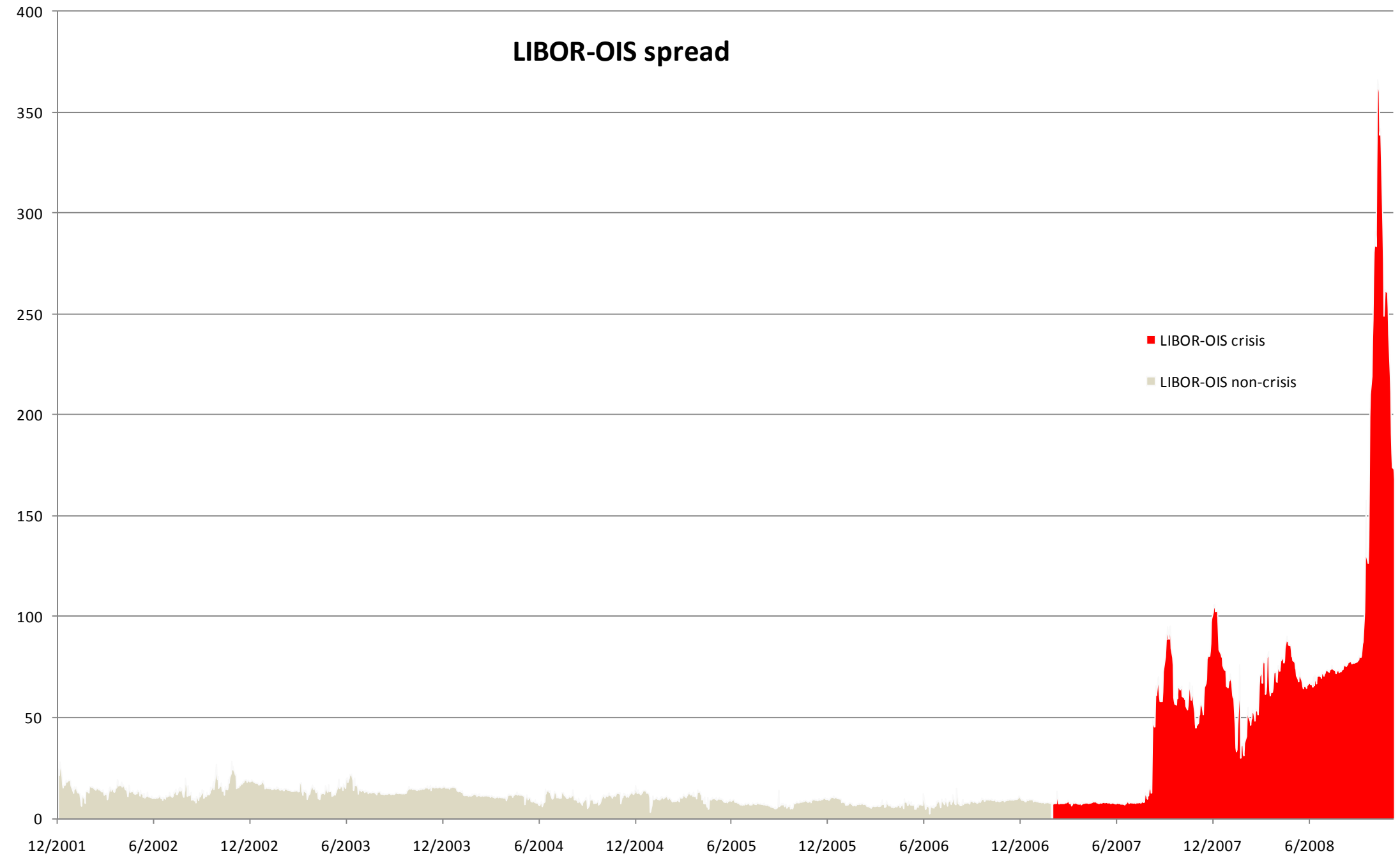


Figure 2: The Libor-OIS and the TED spreads (in basis points)

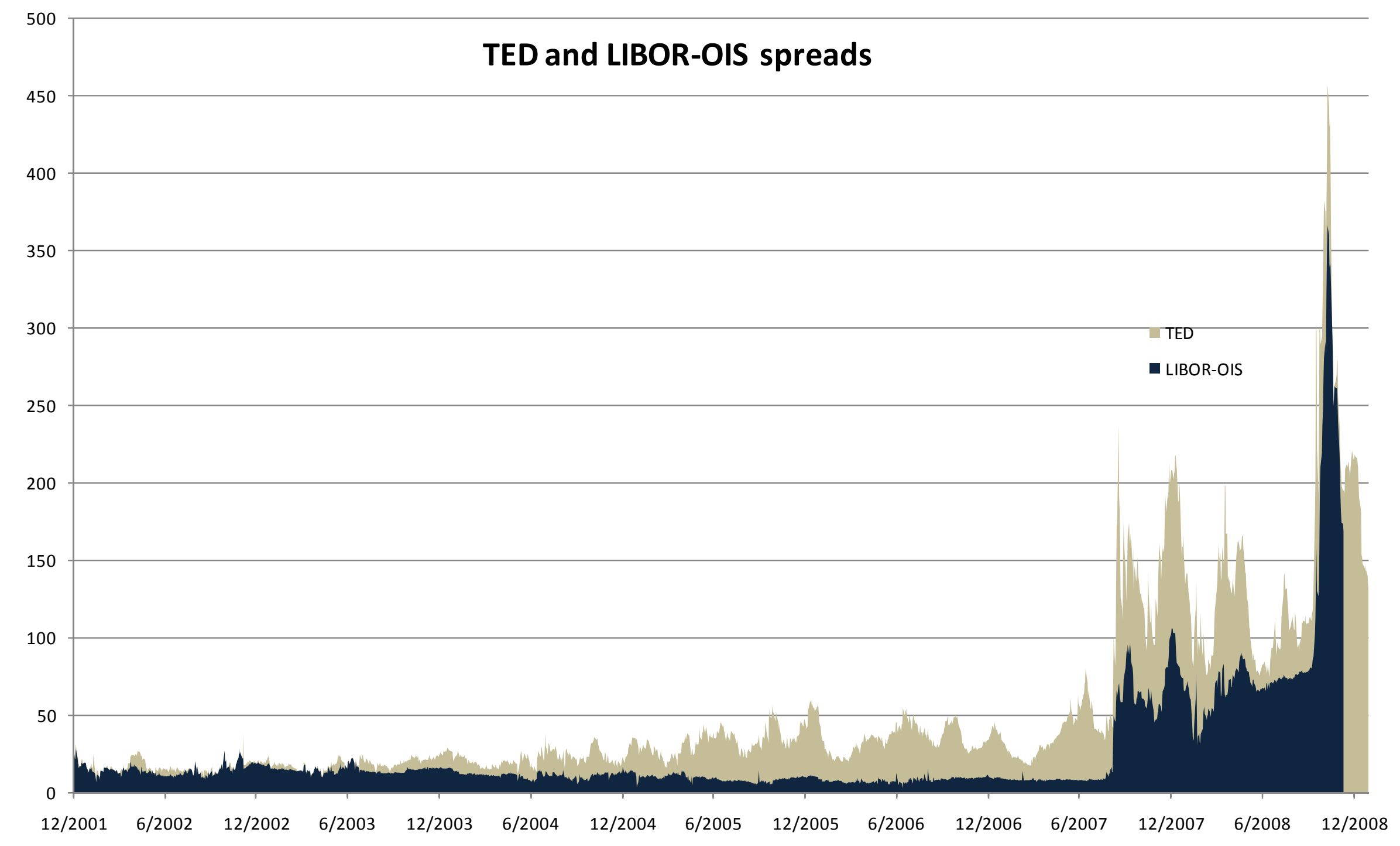


Figure 3: The TED spread (in basis points)

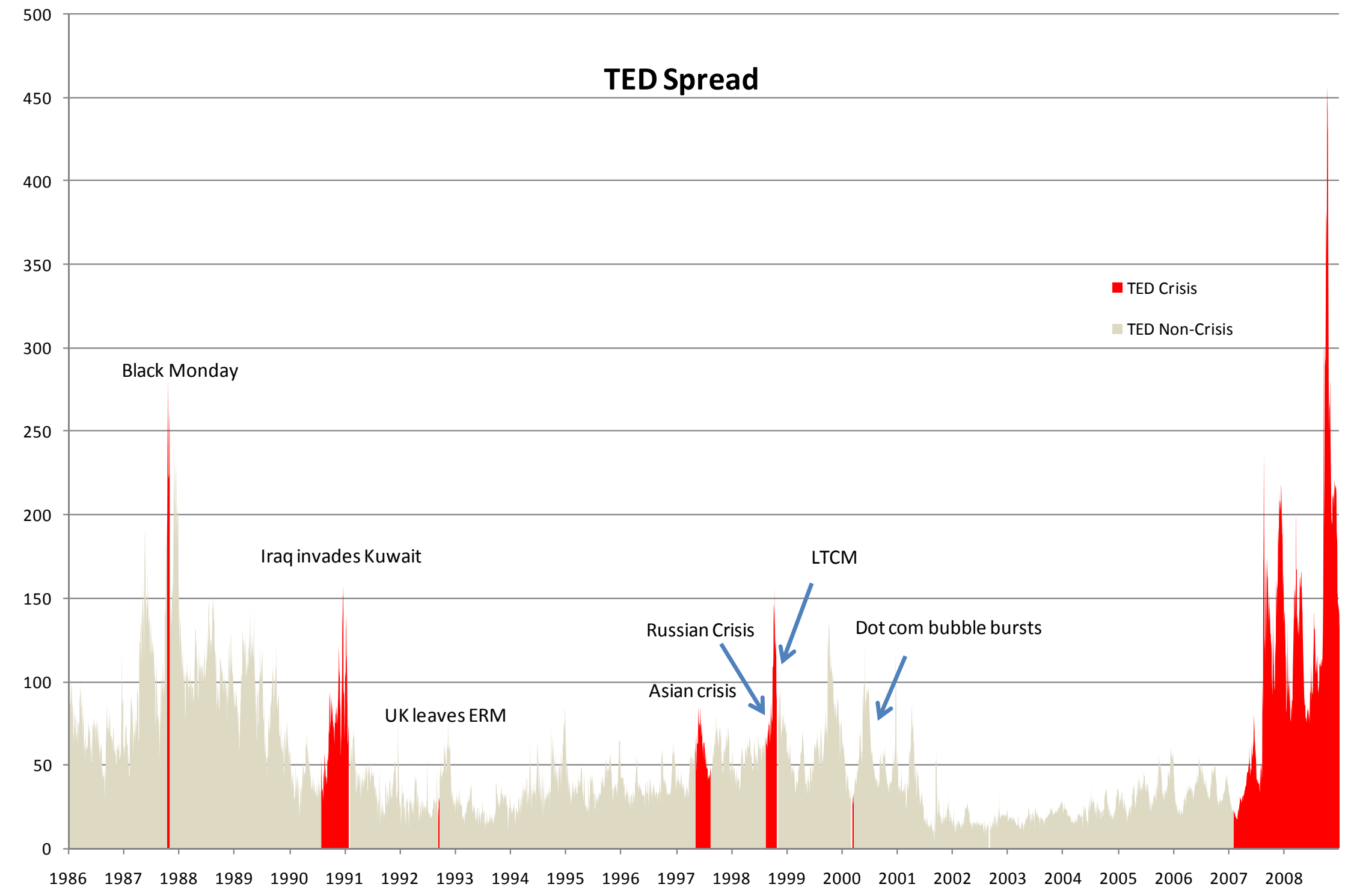




\section{Notes for Figure 3: Crises Dates}

\begin{tabular}{ll}
\hline Dates & Description of Crisis \\
\hline 15 Oct 1987 - 21 Oct 1987 & Black Monday / the 1987 Crash \\
02 Aug 1990 - 01 Feb 1991 & Iraq invasion of Kuwait followed by liberation of Kuwait \\
15 Sep 1992 - 21 Sep 1992 & The U.K. crashes out of the ERM \\
12 May 1997 - 19 Aug 1997 & The Asian financial crisis \\
13 Aug 1998 - 31 Oct 1998 & Russian financial crisis \\
19 Aug 1998 - 01 Oct 1998 & Long Term Capital Management bailout \\
08 Mar 2000 - 15 Mar 2000 & Dot com bubble bursts \\
01 Feb 2007 - 31 Dec 2008 & Subprime mortgage financial crisis \\
\hline
\end{tabular}




Variable
TED spread
Libor-OIS spread
normalized share volume
average normalized share volume over day $\mathrm{t}$ and $\mathrm{t}+1$
market normalized share volume
market average normalized share volume over day $\mathrm{t}$
and $\mathrm{t}+1$
normalized dollar volume
average normalized dollar volume over day $\mathrm{t}$ and
$\mathrm{t}+1$
market normalized dollar volume
market average normalized dollar volume over day $\mathrm{t}$
and $\mathrm{t}+1$
market equal weighted return
market equal weighted return over days $\mathrm{t}$ and $\mathrm{t}+1$

market value weighted return

market value weighted return over days $t$ and $t+1$

$I L L I Q_{i j}=$ Average $\left(\frac{\left|r_{t}\right|}{\text { Volume }_{t}}\right)$

$I L L I Q_{\mathrm{G}}$

Market Share Volume Group $G_{\mathrm{t}}$

Relative Volume of Group $\mathrm{X}$ to $\mathrm{Y}_{\mathrm{t}}$

Holiday
Description of Variable

The three month USD London Interbank Offered Rate (Libor) less the three month T-bill rate.

The three month USD London Interbank Offered Rate (Libor) less the three month USD Overnight Index Swap (OIS) rate.

Share volume in day $t$ divided by the average daily share volume over the previous five day period.

The average of normalized share volume over day $t$ and $t+1$.

The equal-weighted average of normalized share volume over all firms

The average of market normalized share volume over day $t$ and $t+1$.

Daily dollar volume in day t divided by the average daily dollar volume over the previous five day period.

The average of normalized dollar volume over day $t$ and $t+1$.

The equally-weighted average of normalized dollar volume over all firms

The average of market normalized dollar volume over day $t$ and $t+1$.

The daily equally-weighted return of the market. Reported in percent.

The daily two day average equally-weighted return of the market. Reported in percent.

The daily equal weighted return of the market. Reported in percent.

The daily two day average equally-weighted return of the market. Reported in percent.

$r_{t}$ is the return on day $\mathrm{t}$ and Volume $_{t}$ is the dollar trading volume on day $t$ for stock or group $i$. ILLI $Q_{i j}$ is the average of $\left|r_{t}\right|$ /Volume $_{t}$ over all days in month $j$. Throughout the paper we report $I L L I Q_{\mathrm{ij}} \times 10^{6}$ (i.e. volume is measured in millions).

The equally-weighted average of $I L L I Q_{\mathrm{ij}}$ across all stocks that belong to illiquidity group $G$.

The dollar volume of all stocks in illiquidity group $G$ on day $t$ divided by the dollar volume of all stocks in our sample.

The dollar volume of all stocks in illiquidity group $X$ divided by the dollar volume of all stocks in illiquidity group $Y$ on day $t$.

A dummy for holidays set such that if a holiday falls on a Friday then the preceding Thursday is set to 1 , and if the holiday is on a Monday then the following Tuesday is set to 1 , and if the holiday is on any other weekday then the day preceding and following the holiday are set to 1 . This is the same Holiday definition as in Chordia, Roll, and Subrahmanyam (2001). 


\section{Table 1: Descriptive statistics of the Libor-OIS and TED spreads}

We present descriptive statistics of the spreads used in our study. The Libor-OIS spread data covers the period $4^{\text {th }}$ December 2001 to 11 November 2008 . The TED-spread data covers the period $2^{\text {nd }}$ January 1986 to 31 December 2008. Spreads are reported in basis points. We report mean, standard error, standard deviation, coefficient of variation, median, minimum and maximum values. We split our sample into weekdays, holidays, crisis and non-crisis days. Our spread variables and the dummy variable Holiday are described in Appendix A. The notes to Figure 3 lists the crisis dates. For each day of the week, the column Diff reports the difference between the average spread for the given day and the average of all other weekdays (e.g., for Mon, the difference between the spread on Mon and the spread on Tue-Fri). For Crisis (Holiday) days the Diff column reports the difference between Crisis and Non-crisis days (Holidays and NonHolidays). We report the t-statistics for the differences (Diff) in the last column.

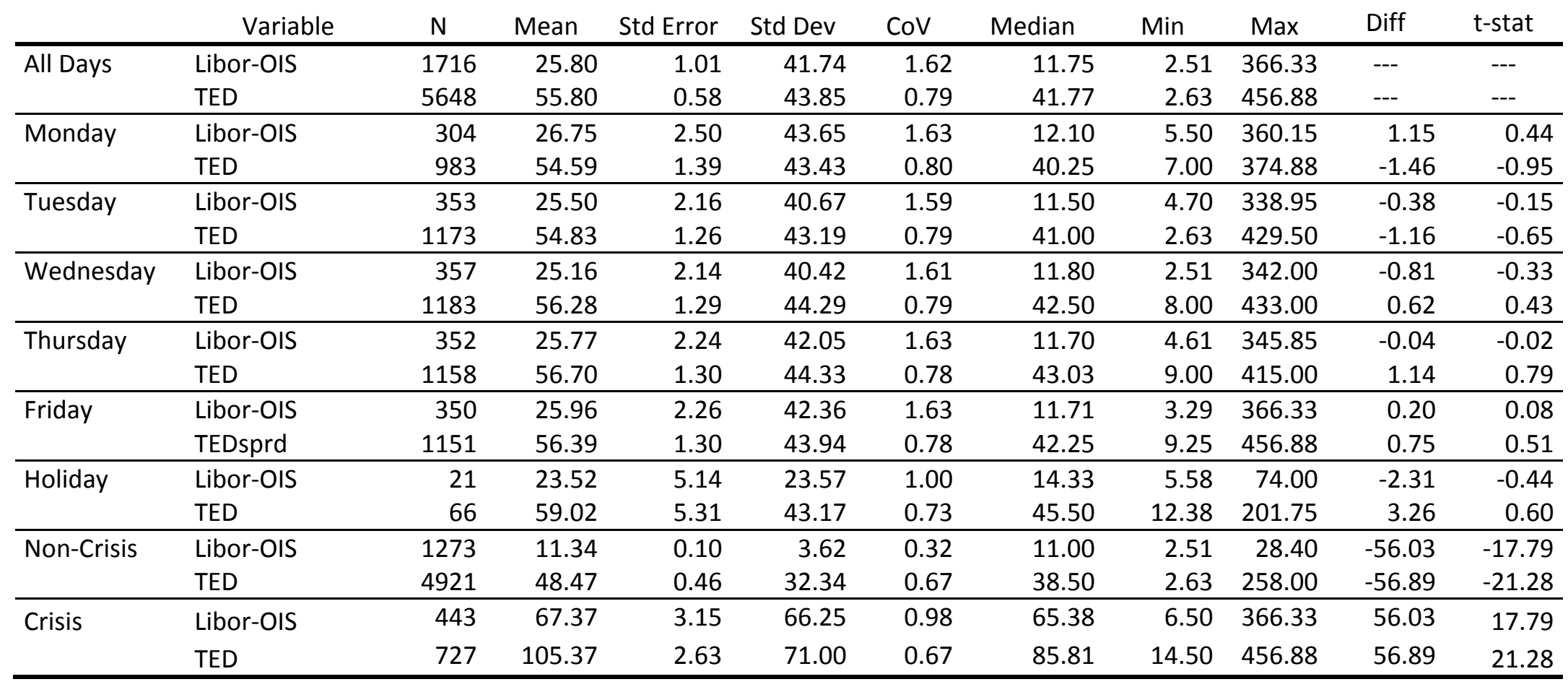




\section{Table 2: Illiquidity group transition probabilities}

Each month, stocks are sorted into illiquidity deciles (1 liquid and 10 illiquid), based on ILLIQ. The table reports the percentage of stocks that are in group $G$ one month and $H$ the next; $G, H=1 \ldots 10$.

\begin{tabular}{|c|c|c|c|c|c|c|c|c|c|c|c|}
\hline & \multicolumn{10}{|c|}{ Illiquidity group in month $\mathrm{t}+1$} \\
\hline & & 1 & 2 & 3 & 4 & 5 & 6 & 7 & 8 & 9 & 10 \\
\hline \multirow{10}{*}{$\begin{array}{l}\text { Illiquidity } \\
\text { group } \\
\text { in month } \mathrm{t}\end{array}$} & 1 & 89.88 & 9.76 & 0.19 & 0.08 & 0.04 & 0.02 & 0.01 & 0.01 & 0.01 & 0.01 \\
\hline & 2 & 9.84 & 72.69 & 16.41 & 0.85 & 0.14 & 0.05 & 0.02 & 0.01 & 0.00 & 0.00 \\
\hline & 3 & 0.23 & 15.61 & 61.07 & 20.36 & 2.21 & 0.39 & 0.09 & 0.02 & 0.01 & 0.00 \\
\hline & 4 & 0.05 & 1.00 & 18.35 & 53.43 & 22.72 & 3.53 & 0.73 & 0.15 & 0.03 & 0.01 \\
\hline & 5 & 0.02 & 0.20 & 2.49 & 19.82 & 48.46 & 23.12 & 4.68 & 0.98 & 0.19 & 0.04 \\
\hline & 6 & 0.01 & 0.06 & 0.50 & 3.61 & 19.90 & 45.88 & 23.52 & 5.33 & 1.02 & 0.18 \\
\hline & 7 & 0.00 & 0.02 & 0.14 & 0.88 & 4.58 & 20.14 & 44.32 & 23.54 & 5.59 & 0.80 \\
\hline & 8 & 0.01 & 0.00 & 0.04 & 0.24 & 1.18 & 5.25 & 20.39 & 44.20 & 24.33 & 4.35 \\
\hline & 9 & 0.01 & 0.00 & 0.02 & 0.06 & 0.27 & 1.22 & 5.33 & 21.58 & 48.14 & 23.36 \\
\hline & 10 & 0.01 & 0.00 & 0.00 & 0.02 & 0.06 & 0.26 & 0.93 & 4.39 & 21.43 & 72.90 \\
\hline
\end{tabular}




\section{Table 3: Descriptive Statistics of Selected Variables}

All variables are defined in Appendix A. The data covers the period $2^{\text {nd }}$ January 1986 to $31^{\text {st }}$ December 2008 . We have 5,802 daily observations of the changes in volume and returns. ILLIQ refers to the Amihud (2002) illiquidity measure: ILLIQ $Q_{i j}=\operatorname{Avg}\left(\left|r_{t}\right| /\right.$ Volume $\left._{t}\right)$, where $r_{t}$ is the return on day $t$ of stock $i$ and Volume Vis the dollar trading volume (in millions). The averaging is done across days in month $j$. There are 1,243,739 firm-month ILLIQ observations. Panel A: Descriptive statistics of the pooled sample. Panel B: For each month, stocks are sorted into ten groups based on their $I L L I Q_{i j}$, with Group 1 consisting of the $10 \%$ most liquid stocks, Group 10 the $10 \%$ most illiquid stocks, etc. Descriptive statistics for each group are provided. Panel C: Descriptive statistics of market normalized share and dollar volume, Relative Volume of Group 10 to Group 1 (multiplied by $10^{3}$ ), Market Share of Volume Group 1, equally and value weighted market returns (in percent).

\section{Panel A: Descriptive statistics of stock illiquidity}

\begin{tabular}{lrrrrrrrr} 
Variable & $\mathrm{N}$ & Mean & Std Err & Std Dev & CoV & Median & Min & Max \\
\hline ILLIQ & $1,243,739$ & 17.632 & 0.566 & 631.266 & 35.802 & 0.134 & 0.000 & 291,059 \\
\hline
\end{tabular}

Panel B: Descriptive statistics of group illiquidity

\begin{tabular}{r|ccrcrrrr}
\multicolumn{1}{c}{ Variable } & Group & $\mathrm{N}$ & Mean & Median & Std Err & Std Dev & Min & Max \\
\hline \multirow{6}{*}{ ILLIQ } & 1 & 124254 & 0.001 & 0.001 & 0.000 & 0.00 & 0.000 & 0.02 \\
& 2 & 124381 & 0.008 & 0.005 & 0.000 & 0.01 & 0.000 & 0.07 \\
& 3 & 124417 & 0.026 & 0.015 & 0.000 & 0.03 & 0.000 & 0.28 \\
& 4 & 124390 & 0.077 & 0.039 & 0.000 & 0.10 & 0.001 & 0.81 \\
& 5 & 124360 & 0.201 & 0.093 & 0.001 & 0.26 & 0.002 & 2.11 \\
& 6 & 124436 & 0.493 & 0.232 & 0.002 & 0.62 & 0.004 & 4.90 \\
& 7 & 124424 & 1.190 & 0.612 & 0.004 & 1.42 & 0.010 & 11.69 \\
& 8 & 124383 & 2.987 & 1.766 & 0.009 & 3.32 & 0.032 & 26.65 \\
& 9 & 124415 & 8.858 & 5.981 & 0.026 & 9.21 & 0.100 & 77.21 \\
& 10 & 124279 & 162.601 & 34.435 & 5.648 & 1991.11 & 0.468 & $291,059.30$ \\
\hline
\end{tabular}

Panel C: Descriptive statistics of market volume and returns

\begin{tabular}{lrrrrrrrr} 
Variable & $\mathrm{N}$ & Mean & Std Err & Std Dev & CoV & Median & Min & Max \\
\hline Market normalized share volume & 5,802 & 1.007 & 0.002 & 0.162 & 0.160 & 0.998 & 0.264 & 2.318 \\
Market normalized dollar volume & 5,802 & 1.009 & 0.002 & 0.183 & 0.181 & 0.994 & 0.245 & 2.689 \\
Relative Volume Group 10 to Group 1 & 5,802 & 0.430 & 0.011 & 0.847 & 1.972 & 0.325 & 0.033 & 29.308 \\
Market Share of Volume Group 1 & 5,802 & 0.786 & 0.001 & 0.047 & 0.060 & 0.788 & 0.564 & 0.915 \\
Market return (equally weighted, \%) & 5,802 & 0.079 & 0.010 & 0.828 & 10.477 & 0.141 & -10.390 & 10.738 \\
Market return (value weighted, \%) & 5,802 & 0.042 & 0.013 & 1.058 & 25.038 & 0.073 & -17.135 & 11.518 \\
\hline
\end{tabular}




\section{Table 4: Correlation Matrix}

All variables are defined in Appendix A. For all correlations except those with the Libor-OIS spread there are 5,648 daily observations from $2^{\text {nd }}$ January 1986 to $31^{\text {st }}$ December 2008. The correlations with the Libor-OIS spread are based on 1,703 daily observations from $4^{\text {th }}$ December 2001 to $11^{\text {th }}$ November 2008 .

\begin{tabular}{|c|c|c|c|c|c|c|c|c|c|c|c|c|}
\hline & 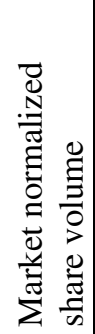 & 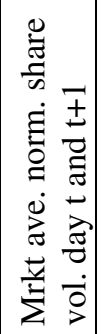 & 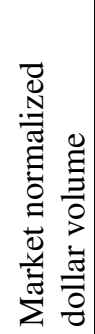 & 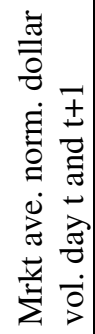 & 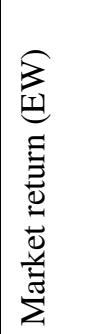 & 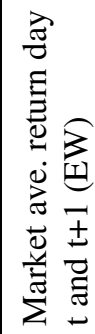 & 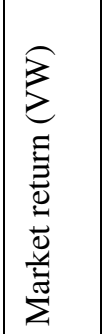 & 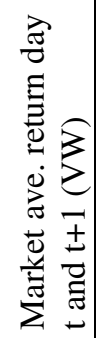 & 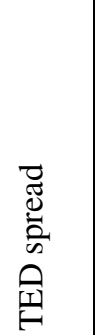 & 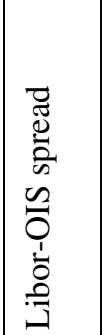 & 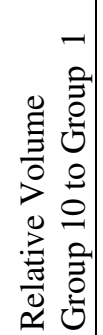 & 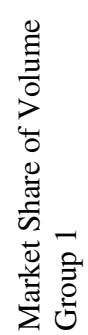 \\
\hline Market normalized share volume & 1 & 0.85 & 0.95 & 0.80 & -0.01 & 0.02 & \begin{tabular}{|l|}
0.02 \\
\end{tabular} & 0.02 & 0.02 & 0.01 & -0.05 & 0.08 \\
\hline Mrkt ave. norm. share vol. day $t$ and $t+1$ & 0.85 & 1 & 0.81 & 0.95 & -0.06 & -0.03 & -0.01 & 0.00 & 0.02 & 0.01 & -0.03 & 0.06 \\
\hline Market normalized dollar volume & 0.95 & 0.81 & 1 & 0.85 & 0.05 & 0.06 & 0.08 & 0.06 & 0.01 & \begin{tabular}{|c|}
-0.02 \\
\end{tabular} & -0.06 & 0.12 \\
\hline Mrkt ave. norm. dollar vol. day $\mathrm{t}$ and $\mathrm{t}+1$ & 0.80 & 0.95 & 0.85 & 1 & 0.01 & 0.03 & 0.05 & 0.06 & 0.00 & \begin{tabular}{|c|}
-0.02 \\
\end{tabular} & -0.04 & 0.09 \\
\hline Market return $(\mathrm{EW})$ & -0.01 & -0.06 & 0.05 & 0.01 & 1 & 0.77 & 0.87 & 0.60 & -0.10 & -0.17 & 0.02 & -0.09 \\
\hline Market ave. return day $t$ and $t+1(\mathrm{EW})$ & 0.02 & \begin{tabular}{|c|}
-0.03 \\
\end{tabular} & 0.06 & 0.03 & 0.77 & 1 & 0.68 & 0.87 & -0.09 & -0.18 & 0.02 & -0.08 \\
\hline Market return (VW) & 0.02 & -0.01 & 0.08 & 0.05 & 0.87 & 0.68 & 1 & 0.71 & -0.05 & -0.13 & 0.01 & -0.04 \\
\hline Market ave. return day $t$ and $t+1(\mathrm{VW})$ & 0.02 & 0.00 & 0.06 & 0.06 & 0.60 & 0.87 & 0.71 & 1 & -0.03 & -0.14 & 0.01 & -0.03 \\
\hline TED spread & 0.02 & 0.02 & 0.01 & 0.00 & -0.10 & -0.09 & -0.05 & -0.03 & 1 & 0.92 & -0.09 & 0.22 \\
\hline Libor-OIS spread & 0.01 & 0.01 & -0.02 & -0.02 & -0.17 & -0.18 & -0.13 & -0.14 & 0.92 & 1 & -0.11 & 0.18 \\
\hline Relative Volume Group 10 to Group 1 & -0.05 & -0.03 & -0.06 & -0.04 & 0.02 & 0.02 & 0.01 & 0.01 & -0.09 & -0.11 & 1 & -0.22 \\
\hline Market Share of Volume Group 1 & 0.08 & 0.06 & 0.12 & 0.09 & -0.09 & 0.08 & -0.04 & -0.03 & 0.22 & 0.18 & -0.22 & 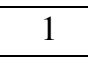 \\
\hline
\end{tabular}




\section{Table 5: Descriptive statistics of spreads on low and high spread days}

For each month in the sample period and each type of spread we: (i) select the two days with the highest and the two days with the lowest spreads; and (ii) average the values of the spread on the two high as well as the two low spread days. If there is a single highest spread day but several second highest spread days, then the latter are weighted equally. For example, if four days have the second highest spread for a particular month then, for that month, each of these four days represent one fourth of a high spread day. We proceed in the analogous way for low spread days. In this way, we generate time series with monthly observations of high and low spreads. The table provides descriptive statistics of these. Spreads are reported in basis points.

\begin{tabular}{lcrrrrrrrr}
\multicolumn{1}{c}{ Spread } & Day & \multicolumn{1}{c}{ N } & Mean & Std Error & Std Dev & \multicolumn{1}{c}{ CoV } & Median & \multicolumn{1}{c}{ Min } & Max \\
\hline TED spread & Low & 276 & 43.14 & 2.01 & 33.33 & 0.77 & 32.72 & 6.31 & 252.31 \\
& High & 276 & 70.11 & 3.22 & 53.55 & 0.76 & 54.39 & 15.28 & 444.94 \\
\hline Libor-OIS & Low & 84 & 21.69 & 3.85 & 35.31 & 1.63 & 10.05 & 3.56 & 243.69 \\
spread & High & 84 & 33.03 & 5.87 & 53.81 & 1.63 & 13.80 & 7.75 & 363.24 \\
\hline TED (Libor- & Low & 84 & 38.88 & 4.74 & 43.42 & 1.12 & 21.05 & 8.16 & 252.31 \\
OIS period) & High & 84 & 62.31 & 8.02 & 73.48 & 1.18 & 34.06 & 15.28 & 444.94 \\
\hline
\end{tabular}




\section{Table 6: High and Low Spread Days: Volume and Returns by Illiquidity Group}

This table presents sorts capturing the effect of spreads on stocks of various levels of illiquidity. All of our variables are defined in Appendix A. In the month prior to the observation month, all of our stocks are sorted into ten groups based on ILLIQ $\mathrm{ij}_{\mathrm{j}}$. The stocks that are in Group 1 are the most liquid while those that are in Group 10 are the least liquid. We identify high and low spread days as in Table 5. For each low (high) spread day we calculate all volume measures for each illiquidity group. For example, for illiquidity Group 1 the normalized share volume is the total share volume of all stocks in Group 1 on day t divided by the average share volume of all stocks in Group 1 over the previous five day period. We then average normalized share volume over high days within each month. Finally, we report the average normalized share volume over all months in our sample. We follow this procedure for all four volume measures. We also report the equally-weighted returns of each illiquidity group. Returns (in percent) are first averaged over low (high) days within the month and then over all months in sample. In Panel A high and low spread days are classified according to the Libor-OIS. In Panel B we follow the exactly same procedure, but use the TED spread to classify high and low days.

\section{Panel A: The Libor-OIS spread}

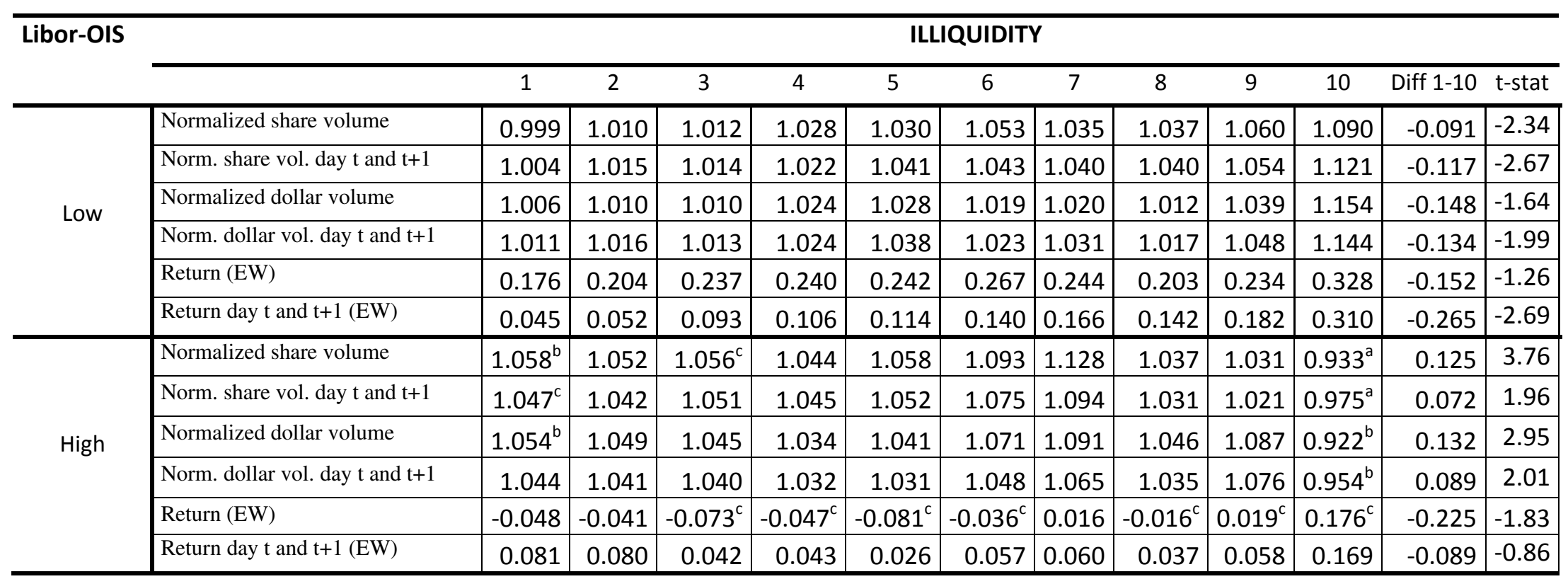

$\mathrm{a}, \mathrm{b}$ and $\mathrm{c}$ denotes statistical significance between in the difference in the variable between high and low spread days at the $1 \%, 5 \%$ and $10 \%$ level respectively. 


\section{Panel B: The TED spread}

\section{ILLIQUIDITY}

\begin{tabular}{|c|c|c|c|c|c|c|c|c|c|c|c|c|c|}
\hline & & 1 & 2 & 3 & 4 & 5 & 6 & 7 & 8 & 9 & 10 & Diff 1-10 & t-stat \\
\hline \multirow{6}{*}{ Low } & Norm & 1.004 & 1.012 & 1.009 & 1.014 & 1.016 & 1.024 & 1.013 & 1.021 & 1.024 & 1.033 & -0.030 & -1.72 \\
\hline & Norm. share vol. day $\mathrm{t}$ and $\mathrm{t}+1$ & 1.016 & 1.025 & 1.022 & 1.020 & 1.022 & 1.033 & 1.016 & 1.022 & 1.028 & 1.039 & -0.022 & -1.33 \\
\hline & Normalized dollar volume & 1.005 & 1.013 & 1.010 & 1.014 & 1.018 & 1.019 & 1.008 & 1.010 & 1.022 & 1.021 & -0.016 & -0.77 \\
\hline & Norm. dollar v & 1.017 & 1.024 & 1.023 & 1.020 & 1.026 & 1.027 & 1.013 & 1.017 & 1.031 & 1.035 & -0.018 & -0.85 \\
\hline & Return (EW) & 0.107 & 0.126 & 0.132 & 0.135 & 0.133 & 0.138 & 0.109 & 0.120 & 0.163 & 0.369 & -0.262 & -4.14 \\
\hline & Return day $\mathrm{t}$ and $\mathrm{t}+1(\mathrm{EW})$ & 0.038 & 0.043 & 0.061 & 0.062 & 0.061 & 0.073 & .079 & .096 & 0.152 & 0.385 & -0.348 & -6.37 \\
\hline \multirow{6}{*}{ High } & Normalized share volume & $1.052^{\mathrm{a}}$ & $1.041^{b}$ & $1.034^{\mathrm{c}}$ & 1.032 & 1.038 & 1.034 & 1.040 & 1.028 & 1.036 & $0.997^{c}$ & 0.056 & 3.22 \\
\hline & Norm. share vol. day $\mathrm{t}$ and $\mathrm{t}+1$ & 1.035 & 1.029 & 1.023 & 1.031 & 1.034 & 1.038 & 1.032 & 1.024 & 1.032 & 1.003 & 0.032 & 1.75 \\
\hline & Normalized dollar volume & $1.050^{\mathrm{a}}$ & $1.040^{b}$ & 1.029 & 1.031 & 1.035 & 1.035 & 1.044 & $1.052^{\mathrm{C}}$ & 1.036 & 1.004 & 0.046 & 2.29 \\
\hline & Norm. dollar vol. day $\mathrm{t}$ and $\mathrm{t}+1$ & 1.035 & 1.028 & 1.021 & 1.027 & 1.036 & 1.034 & 1.031 & 1.048 & 1.022 & 1.042 & -0.007 & -0.18 \\
\hline & Return (EW) & 0.004 & 0.002 & -0.006 & 0.001 & -0.013 & -0.014 & 0.016 & 0.049 & 0.089 & 0.359 & -0.355 & -4.42 \\
\hline & Return day $\mathrm{t}$ and $\mathrm{t}+1$ (EW) & 0.119 & 0.124 & 0.109 & 0.108 & $0.086^{\mathrm{c}}$ & $0.078^{c}$ & $0.090^{c}$ & 0.087 & 0.118 & 0.391 & -0.272 & -4.71 \\
\hline
\end{tabular}

$\mathrm{a}, \mathrm{b}$ and $\mathrm{c}$ denotes statistical significance between in the difference in the variable between high and low spread days at the $1 \%, 5 \%$ and $10 \%$ level respectively. 


\section{Table 7: Differences in Volume and Returns between High and Low Spread Days}

We present results of the difference in changes in volume between high and low spread days over illiquidity groups. All of our variables are defined in Appendix A. In the month prior to the observation month, all of our stocks are sorted into ten groups based on ILLIQ $\mathrm{i}_{\mathrm{ij}}$. We identify high and low spread days as in Table 5 . We calculate our volume and return measures for high and low spread days separately as described in Table 6. For each month we average our measures over all low (high) days. We then subtract the average value of the measure on low days from the average value of the measure on high days over all sample months. Finally, we report the monthly average difference between high and low spread days for our measure. In Panel A high and low spread days are classified according to the Libor-OIS. In Panel B we follow the exactly same procedure, but use the TED spread to classify high and low days. Returns are in percent.

\section{Panel A: Libor-OIS spread}

\section{ILLIQUIDITY}

\begin{tabular}{|c|c|c|c|c|c|c|c|c|c|c|c|c|}
\hline Hig & 1 & 2 & 3 & 4 & 5 & 6 & 7 & $\varepsilon$ & 9 & 10 & 10 & $-s t$ \\
\hline Nor1 & לבט & 0.042 & 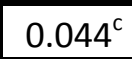 & 0.016 & 0.021 & 0.039 & 0.093 & -0.001 & -0.029 & + & 0.216 & 4.04 \\
\hline Norn & $043^{c}$ & 0 & & & & 32 & & & & 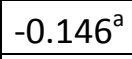 & & 3.26 \\
\hline Norm & $048^{b}$ & 0.039 & 0.035 & 0.010 & & 0.052 & 0.071 & 34 & 0.047 & -0.2 & 280 & 2.81 \\
\hline Norm. & 3 &. & 0.0 & 0.008 & -0.008 & 0.025 & 0.035 & 0.017 & 0.027 & -0.15 & 0.223 & 2.69 \\
\hline Ret & 224 & -0.245 & $-0.310^{c}$ & $-0.287^{c}$ & $-0.323^{c}$ & $-0.304^{c}$ & -0.228 & $-0.219^{c}$ & $-0.215^{c}$ & $-0.152^{c}$ & -0.072 & -0.39 \\
\hline eturn EW $(t, t+1)$ & 036 & 0.028 & -0.051 & -0.063 & -0.088 & -0.083 & -0.106 & -0.104 & -0.125 & -0.141 & 0.177 & 1.17 \\
\hline
\end{tabular}

Panel B: TED spread

\section{ILLIQUIDITY}

\begin{tabular}{|c|c|c|c|c|c|c|c|c|c|c|c|c|}
\hline Hig & 1 & 2 & 3 & 4 & 5 & 6 & 7 & 8 & 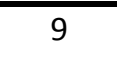 & 0 & 0 & -stat \\
\hline le & & c & $r$ & 0.017 & 0.022 & 0.011 & $0<1$ & 0.007 & .012 & 1.0.0 & 0.086 & 3.28 \\
\hline orm & 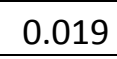 & 4 & 001 & 0 & 2 & 05 & 6 & 0.003 & 4 & & .055 & 2.04 \\
\hline Norma & $046^{a}$ & $0.027^{b}$ & 0.019 & 0.018 & 0.011 & 0.016 & 0.036 & $0.042^{c}$ & .014 & -0.017 & .062 & 2.03 \\
\hline Norm & 8 & 4 & -0.002 & 0.007 & 0.010 & 0.007 & 0.018 & 0.031 & -0.009 & 007 & 0.011 & 0.23 \\
\hline Return & 3 & 4 & 8 & -0. & .146 & 52 & -0.093 & -0.071 & -0 & 0 & 0.093 & -0.97 \\
\hline eturn EW $(t, t+1)$ & 0.081 & 0.080 & 0.048 & 0.046 & $0.025^{c}$ & $0.005^{c}$ & $0.012^{c}$ & -0.009 & -0.034 & 0.006 & 0.076 & 1.06 \\
\hline
\end{tabular}


Table 8: Regression analysis: Differences in Changes in Volume and Illiquidity

This table documents the relation between the differences in normalized share volume between low and high spread days and illiquidity. All of our variables are defined in Appendix A. High and low spread days are classified as in Table 5. We split our sample into ten groups based on ILLIQ $\mathrm{ij}_{\mathrm{j}}$ in the previous month. Our dependent variable is the monthly difference in normalized share volume between low and high spread days for each illiquidity group. We calculate the monthly mean normalized share volume for high and low days as in Table 6. For each month and illiquidity group, we then subtract the mean normalized share volume on low days from the mean normalized share volume on high days to get our dependent variable $\left(\mathrm{HSVOL}_{\mathrm{G}, \mathrm{m}}-\mathrm{LSVOL}_{\mathrm{G}, \mathrm{m}}\right)$. Subscripts $\mathrm{G}$ and $\mathrm{m}$ refer to illiquidity group and month respectively. Our independent variable is ILLIQ $_{\mathrm{G}, \mathrm{m}-1}$, the mean ILLIQ for illiquidity group $\mathrm{G}$ in month $\mathrm{m}-1$. For each month $\mathrm{m}$ in our sample we estimate the following cross-sectional regression:

$$
\operatorname{HSVOL}_{\mathrm{G}, \mathrm{m}}-\mathrm{LSVOL}_{\mathrm{G}, \mathrm{m}}=\alpha_{\mathrm{m}}+\beta_{\mathrm{m}} \times \operatorname{ILLIQ}_{\mathrm{G}, \mathrm{m}-1}+\varepsilon_{\mathrm{G}, \mathrm{m}}
$$

We report the average of all the cross-sectional coefficient estimates $\left(\alpha_{\mathrm{m}}, \beta_{\mathrm{m}}\right)$ with corresponding t-statistics. Standard errors are estimated using the Newey-West procedure with three lags. In specification (1) we use the TED spread as the basis for high and low spread. Specification (2) is identical to specification (1) except that we use the Libor-OIS spread to identify high and low spread days. Specification (3) uses the TED spread, but considers the time period for which the Libor-OIS is available. Specifications (4) and (5) use the TED and Libor-OIS spread respectively, but consider the period prior to the financial crisis (07/2007).

Illiquidity and the difference in normalized volume on high and low spread days

\begin{tabular}{lcccccc}
\hline Spread / Period & Intercept & t-stat & ILLIQ $_{G}$ & t-stat & Adj. R & N \\
\hline (1) TED & 0.023 & $(1.91)$ & -0.0042 & $(-2.28)$ & $14.28 \%$ & 275 \\
\hline (2) LIBOR-OIS & 0.034 & $(1.14)$ & -0.0150 & $(-1.80)$ & $18.07 \%$ & 83 \\
(3) TED (OIS-period) & 0.019 & $(0.76)$ & -0.0125 & $(-2.21)$ & $20.30 \%$ & 83 \\
\hline (4) TED (pre 07/2007) & 0.019 & $(1.71)$ & -0.0040 & $(-2.05)$ & $13.70 \%$ & 257 \\
(5) LIBOR-OIS (pre 07/2007) & 0.026 & $(0.80)$ & -0.0168 & $(-2.79)$ & $16.49 \%$ & 66 \\
\hline
\end{tabular}


Table 9: Market share of volume and spreads

We investigate the relation between the market share of volume of each illiquidity group and the TED and Libor-OIS spreads. We divide the market share volume of each illiquidity group by its time-series average to facilitate comparison between groups. Specifications (1) to (10) estimate the following daily time-series regression:

$$
\frac{\text { Market Share of Volume Group } \mathrm{G}_{t}}{\text { mean (Market Share of Volume Group G) }}=\alpha+\beta \times \text { spread }_{t}+\varepsilon_{t}
$$

where $G$ refers to illiquidity group $G$. Estimation is performed using the Cochrane-Orcutt procedure. In Panel A we use the TED spread as our independent variable. Panel B is identical to Panel A except that we consider the Libor-OIS spread as the independent variable. In Panel $\mathrm{C}$ we use the TED spread, but consider the period for which the Libor-OIS spread is available. Spreads are measured in percentage points.

\section{Panel A: Market share of volume and the TED spread}

\begin{tabular}{lclcccc}
\hline $\begin{array}{l}\text { Dependent Variable } \\
\text { Market share of: }\end{array}$ & Intercept & t-stat & Spread & t-stat & Adj. R & $\mathrm{N}$ \\
\hline Group 1 & 1.002 & $(233.61)$ & 0.0214 & $(5.47)$ & $0.51 \%$ & 5647 \\
Group 2 & 1.001 & $(96.36)$ & -0.062 & $(-5.11)$ & $0.44 \%$ & 5647 \\
\hline Group 3 & 1.002 & $(60.07)$ & -0.085 & $(-4.96)$ & $0.42 \%$ & 5647 \\
Group 4 & 0.987 & $(42.71)$ & -0.090 & $(-4.23)$ & $0.30 \%$ & 5647 \\
\hline Group 5 & 0.977 & $(41.53)$ & -0.1143 & $(-4.38)$ & $0.32 \%$ & 5647 \\
Group 6 & 0.965 & $(41.38)$ & -0.1347 & $(-4.67)$ & $0.37 \%$ & 5647 \\
\hline Group 7 & 0.966 & $(38.02)$ & -0.1605 & $(-5.07)$ & $0.44 \%$ & 5647 \\
Group 8 & 0.940 & $(31.76)$ & -0.1449 & $(-3.93)$ & $0.25 \%$ & 5647 \\
\hline Group 9 & 0.939 & $(23.17)$ & -0.1378 & $(-2.60)$ & $0.10 \%$ & 5647 \\
Group 10 & 0.982 & $(15.36)$ & -0.2288 & $(-2.64)$ & $0.11 \%$ & 5647 \\
\hline
\end{tabular}

Panel B: Market share of volume and the Libor-OIS spread

\begin{tabular}{lclllll}
\hline $\begin{array}{l}\text { Dependent Variable } \\
\text { Market share of: }\end{array}$ & Intercept & t-stat & Spread & t-stat & Adj. R & N \\
\hline Group 1 & 0.961 & $(144.92)$ & 0.0263 & $(2.51)$ & $0.31 \%$ & 1702 \\
Group 2 & 1.092 & $(91.64)$ & -0.0250 & $(-1.11)$ & $0.01 \%$ & 1702 \\
\hline Group 3 & 1.200 & $(55.26)$ & -0.1079 & $(-2.74)$ & $0.38 \%$ & 1702 \\
Group 4 & 1.262 & $(33.95)$ & -0.1932 & $(-3.10)$ & $0.50 \%$ & 1702 \\
\hline Group 5 & 1.177 & $(25.30)$ & -0.1642 & $(-2.11)$ & $0.20 \%$ & 1702 \\
Group 6 & 1.096 & $(27.15)$ & -0.2487 & $(-3.28)$ & $0.57 \%$ & 1702 \\
\hline Group7 & 0.946 & $(25.55)$ & -0.2826 & $(-3.95)$ & $0.85 \%$ & 1702 \\
Group 8 & 0.774 & $(22.81)$ & -0.2865 & $(-4.39)$ & $1.06 \%$ & 1702 \\
\hline Group 9 & 0.778 & $(12.31)$ & -0.3113 & $(-2.47)$ & $0.30 \%$ & 1702 \\
Group 10 & 1.064 & $(6.70)$ & -0.6250 & $(-1.96)$ & $0.17 \%$ & 1702 \\
\hline
\end{tabular}


Panel C: Market share of volume and the TED spread over the Libor-OIS period

\begin{tabular}{lcccccc}
\hline $\begin{array}{l}\text { Dependent Variable } \\
\text { Market share of: }\end{array}$ & Intercept & t-stat & Spread & t-stat & Adj. R & $\mathrm{N}$ \\
\hline Group 1 & 0.965 & $(138.98)$ & 0.0057 & $(0.93)$ & $-0.01 \%$ & 1702 \\
Group 2 & 1.082 & $(86.01)$ & 0.0078 & $(0.53)$ & $-0.04 \%$ & 1702 \\
\hline Group 3 & 1.180 & $(50.19)$ & -0.0168 & $(-0.67)$ & $-0.03 \%$ & 1702 \\
Group 4 & 1.236 & $(30.95)$ & -0.0484 & $(-1.29)$ & $0.04 \%$ & 1702 \\
\hline Group 5 & 1.157 & $(23.34)$ & -0.0473 & $(-1.01)$ & $0.00 \%$ & 1702 \\
Group 6 & 1.060 & $(23.53)$ & -0.0565 & $(-1.11)$ & $0.01 \%$ & 1702 \\
\hline Group 7 & 0.922 & $(21.93)$ & -0.1000 & $(-2.00)$ & $0.18 \%$ & 1702 \\
Group 8 & 0.761 & $(20.03)$ & -0.1250 & $(-2.79)$ & $0.40 \%$ & 1702 \\
\hline Group 9 & 0.765 & $(10.98)$ & -0.1394 & $(-1.58)$ & $0.09 \%$ & 1702 \\
Group 10 & 1.076 & $(6.17)$ & -0.3550 & $(-1.59)$ & $0.09 \%$ & 1702 \\
\hline
\end{tabular}


Table 10: Relative volume of illiquidity groups and spreads

We investigate the relation between the relative volume (Relative Volume of Group $\mathrm{X}$ to Group $\mathrm{Y}_{\mathrm{t}}$, defined in Appendix A) and the TED and Libor-OIS spreads. We divide relative volume by its time-series average to facilitate comparison between specifications. We estimate the following daily time-series regression:

$$
\frac{\text { Relative Volume of Group X to Group } \mathrm{Y}_{\mathrm{t}}}{\text { mean (Relative Volume of Group X to Group Y) }}=\alpha+\beta \times \text { spread }_{t}+\varepsilon_{t}
$$

where $\mathrm{X}$ and $\mathrm{Y}$ refer to illiquidity groups, $\mathrm{X}>\mathrm{Y}$. We use the Cochrane-Orcutt procedure. In Panel A we report the estimates of $\beta$ when using the TED spread as our independent variable with corresponding t-statistics in brackets below. Each cell reports $\beta$ for the relative volume of different ILLIQ groups. Columns refer to the group of the numerator and rows refer to the group of the denominator (e.g., the upper leftmost cell reports results for when Relative Volume of Group 2 to 1 is the dependent variable). Panel B is identical to Panel A except that we consider the Libor-OIS spread as independent variable. Panel C considers the TED spread over the same period that the Libor-OIS spread is available. Spreads are measured in percentage points.

\section{Panel A: The impact of the TED spread on relative volume}

\begin{tabular}{|c|c|c|c|c|c|c|c|c|c|}
\hline & \multicolumn{9}{|c|}{ Group of numerator } \\
\hline & 2 & 3 & 4 & 5 & 6 & 7 & 8 & 9 & 10 \\
\hline \multirow[t]{2}{*}{1} & -0.084 & -0.103 & -0.109 & -0.138 & -0.177 & -0.205 & -0.192 & -0.188 & -0.297 \\
\hline & $(-5.18)$ & $(-4.75)$ & $(-4.11)$ & $(-4.28)$ & $(-4.91)$ & $(-5.28)$ & $(-4.32)$ & $(-3.00)$ & $(-2.80)$ \\
\hline \multirow[t]{2}{*}{2} & & -0.073 & -0.080 & -0.106 & -0.111 & -0.125 & -0.098 & -0.078 & -0.171 \\
\hline & & $(-7.50)$ & $(-4.69)$ & $(-4.77)$ & $(-4.17)$ & $(-3.78)$ & $(-2.37)$ & $(-1.32)$ & $(-1.97)$ \\
\hline \multirow[t]{2}{*}{3} & & & -0.041 & -0.044 & -0.047 & -0.059 & -0.034 & -0.007 & -0.063 \\
\hline & & & $(-4.23)$ & $(-2.70)$ & $(-2.15)$ & $(-1.99)$ & $(-0.85)$ & $(-0.12)$ & $(-0.83)$ \\
\hline \multirow[t]{2}{*}{4} & & & & 0.005 & -0.007 & -0.016 & 0.011 & 0.032 & -0.000 \\
\hline & & & & $(0.42)$ & $(-0.38)$ & $(-0.57)$ & $(0.29)$ & $(0.59)$ & $(-0.00)$ \\
\hline \multirow[t]{2}{*}{5} & & & & & -0.005 & -0.003 & 0.031 & 0.056 & 0.015 \\
\hline & & & & & $(-0.39)$ & $(-0.15)$ & $(0.99)$ & $(1.17)$ & $(0.22)$ \\
\hline \multirow[t]{2}{*}{6} & & & & & & -0.001 & 0.031 & 0.044 & -0.011 \\
\hline & & & & & & $(-0.09)$ & $(1.14)$ & $(0.99)$ & $(-0.18)$ \\
\hline \multirow[t]{2}{*}{7} & & & & & & & 0.018 & 0.021 & -0.064 \\
\hline & & & & & & & $(0.89)$ & $(0.57)$ & $(-0.99)$ \\
\hline \multirow[t]{2}{*}{8} & & & & & & & & 0.011 & -0.087 \\
\hline & & & & & & & & $(0.36)$ & $(-1.27)$ \\
\hline \multirow[t]{2}{*}{9} & & & & & & & & & -0.116 \\
\hline & & & & & & & & & $(-1.35)$ \\
\hline
\end{tabular}


Panel B: The impact of the Libor-OIS spread on the relative volume

\begin{tabular}{|c|c|c|c|c|c|c|c|c|c|}
\hline & \multicolumn{9}{|c|}{ Group of numerator } \\
\hline & 2 & 3 & 4 & 5 & 6 & 7 & 8 & 9 & 10 \\
\hline 1 & $\begin{array}{l}-0.063 \\
(-1.84)\end{array}$ & $\begin{array}{l}-0.154 \\
(-2.92)\end{array}$ & $\begin{array}{l}-0.255 \\
(-3.28)\end{array}$ & $\begin{array}{l}-0.239 \\
(-2.53)\end{array}$ & $\begin{array}{l}-0.326 \\
(-3.61)\end{array}$ & $\begin{array}{l}-0.362 \\
(-4.23)\end{array}$ & $\begin{array}{l}-0.362 \\
(-4.52)\end{array}$ & $\begin{array}{l}-0.382 \\
(-2.52)\end{array}$ & $\begin{array}{l}-0.746 \\
(-1.95)\end{array}$ \\
\hline 2 & & $\begin{array}{l}-0.081 \\
(-4.66)\end{array}$ & $\begin{array}{l}-0.157 \\
(-3.74)\end{array}$ & $\begin{array}{l}-0.140 \\
(-2.19)\end{array}$ & $\begin{array}{l}-0.224 \\
(-3.38)\end{array}$ & $\begin{array}{l}-0.268 \\
(-4.14)\end{array}$ & $\begin{array}{l}-0.283 \\
(-4.49)\end{array}$ & $\begin{array}{l}-0.304 \\
(-2.35)\end{array}$ & $\begin{array}{l}-0.609 \\
(-1.99)\end{array}$ \\
\hline 3 & & & $\begin{array}{l}-0.073 \\
(-3.21)\end{array}$ & $\begin{array}{l}-0.073 \\
(-1.62)\end{array}$ & $\begin{array}{l}-0.143 \\
(-2.85)\end{array}$ & $\begin{array}{l}-0.195 \\
(-3.78)\end{array}$ & $\begin{array}{l}-0.217 \\
(-4.35)\end{array}$ & $\begin{array}{l}-0.234 \\
(-2.25)\end{array}$ & $\begin{array}{l}-0.511 \\
(-1.97)\end{array}$ \\
\hline 4 & & & & $\begin{array}{l}-0.028 \\
(-1.34)\end{array}$ & $\begin{array}{l}-0.085 \\
(-2.75)\end{array}$ & $\begin{array}{l}-0.148 \\
(-4.17)\end{array}$ & $\begin{array}{l}-0.174 \\
(-4.68)\end{array}$ & $\begin{array}{l}-0.190 \\
(-2.23)\end{array}$ & $\begin{array}{l}-0.437 \\
(-1.87)\end{array}$ \\
\hline 5 & & & & & $\begin{array}{l}-0.067 \\
(-3.98)\end{array}$ & $\begin{array}{l}-0.144 \\
(-5.29)\end{array}$ & $\begin{array}{l}-0.176 \\
(-5.28)\end{array}$ & $\begin{array}{l}-0.190 \\
(-2.49)\end{array}$ & $\begin{array}{l}-0.438 \\
(-1.97)\end{array}$ \\
\hline 6 & & & & & & $\begin{array}{l}-0.111 \\
(-4.70)\end{array}$ & $\begin{array}{l}-0.157 \\
(-4.81)\end{array}$ & $\begin{array}{l}-0.174 \\
(-2.15)\end{array}$ & $\begin{array}{l}-0.437 \\
(-2.06)\end{array}$ \\
\hline 7 & & & & & & & $\begin{array}{l}-0.101 \\
(-2.68)\end{array}$ & $\begin{array}{l}-0.130 \\
(-1.58)\end{array}$ & $\begin{array}{l}-0.450 \\
(-1.97)\end{array}$ \\
\hline 8 & & & & & & & & $\begin{array}{l}-0.049 \\
(-0.73)\end{array}$ & $\begin{array}{l}-0.427 \\
(-1.69)\end{array}$ \\
\hline 9 & & & & & & & & & $\begin{array}{l}-0.411 \\
(-1.29)\end{array}$ \\
\hline
\end{tabular}


Panel C: The impact of the TED on the relative volume during the Libor-OIS period

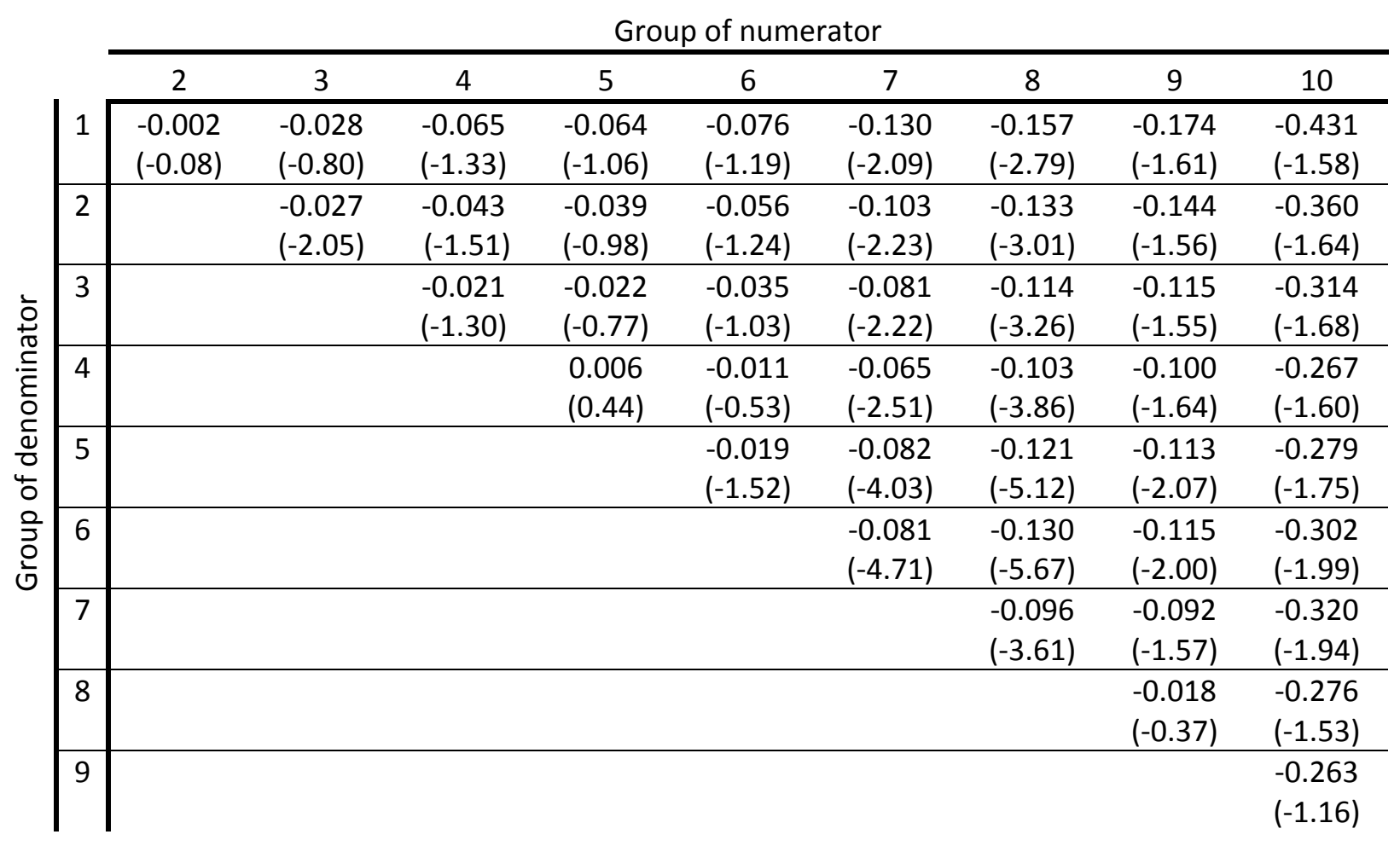


Table 11: Regression analysis: Spreads, Illiquidity and Individual Stock Volume

We examine the relation between spreads, illiquidity and individual stock volume. All of our variables are defined in Appendix A. Our dependent variable is daily normalized share volume at the stock level. We remove observations with normalized share volume greater than five. Group ${ }_{1}$ is a dummy variable that takes the value 1 if a stock belongs to illiquidity Group 1 (i.e., the bottom ten percent in terms of illiquidity), 0 otherwise. Group 2 to Group 10 are dummy variables that take the value 1 if a stock belongs to that liquidity group. Our main independent variables are the Libor-OIS and the TED spread interacted with the illiquidity dummy variable, i.e., spread $\times \operatorname{Group}_{1}, \ldots, \operatorname{spread} \times \operatorname{Group}_{10}$. We estimate the following pooled panel regression:

$$
\text { normalized share volume }{ }_{\mathrm{it}}=\alpha+\beta_{1} \times \operatorname{spread}_{\mathrm{t}} \times \operatorname{Group}_{1, \mathrm{it}}+\ldots+\beta_{10} \times \operatorname{spread}_{\mathrm{t}} \times \operatorname{Group}_{10, \mathrm{it}}+\varepsilon_{\mathrm{it}}
$$

where $i$ refers to firm and $t$ refers to day. Groups are formed the previous calendar month. In some specifications we use as a control variable the market normalized share volume. Standard errors are clustered around time. In Panel A we use the TED spread as spread variable, in Panel B we consider the Libor-OIS and in Panel C we consider the TED spread over the Libor-OIS period. Spreads are measured in percentage points.

\section{Panel A: The TED spread}

\begin{tabular}{|c|c|c|c|c|}
\hline & \multicolumn{2}{|c|}{ (1) } & \multicolumn{2}{|c|}{ (2) } \\
\hline & estimate & t-stat & estimate & t-stat \\
\hline intercept & 0.967 & $(304.37)$ & 0.9677 & $(289.77)$ \\
\hline MRKT NORM. SHARE VOL. & -- & -- & -0.0004 & $(-0.70)$ \\
\hline${\text { spread } \times \text { Group }_{1}}$ & 0.0959 & $(15.31)$ & 0.0960 & $(15.29)$ \\
\hline${\text { spread } \times \text { Group }_{2}}$ & 0.0977 & $(16.38)$ & 0.0979 & $(16.35)$ \\
\hline 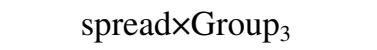 & 0.0856 & $(14.14)$ & 0.0858 & $(14.12)$ \\
\hline${\text { spread } \times \text { Group }_{4}}$ & 0.0726 & $(12.00)$ & 0.0728 & (11.98) \\
\hline${\text { spread } \times \text { Group }_{5}}$ & 0.0543 & (9.06) & 0.0544 & $(9.05)$ \\
\hline${\text { spread } \times \text { Group }_{6}}$ & 0.0319 & $(5.32)$ & 0.0321 & $(5.32)$ \\
\hline${\text { spread } \times \text { Group }_{7}}$ & 0.0027 & $(0.47)$ & 0.0029 & $(0.49)$ \\
\hline${\text { spread } \times \text { Group }_{8}}$ & -0.0422 & $(-7.46)$ & -0.0421 & $(-7.42)$ \\
\hline${\text { spread } \times \text { Group }_{9}}$ & -0.1065 & $(-17.53)$ & -0.1064 & $(-17.50)$ \\
\hline${\operatorname{spread} \times \text { Group }_{10}}$ & -0.2229 & $(-29.61)$ & -0.2228 & $(-29.61)$ \\
\hline Clustering & \multicolumn{2}{|c|}{ Time } & \multicolumn{2}{|c|}{ Time } \\
\hline Adj $R^{2}$ & \multicolumn{2}{|c|}{$0.55 \%$} & \multicolumn{2}{|c|}{$0.55 \%$} \\
\hline $\mathrm{N}$ & \multicolumn{2}{|c|}{$24,429,664$} & \multicolumn{2}{|c|}{$24,429,664$} \\
\hline
\end{tabular}


Panel B: The Libor-OIS spread

\begin{tabular}{|c|c|c|c|c|}
\hline & & & & \\
\hline & Cstiminate & t-stat & Cstimiante & t-stal \\
\hline intercept & 1.0121 & $(257.52)$ & 0.8675 & $(22.50)$ \\
\hline MRKT NORM. SHARE VOL. & -- & -- & 0.1055 & (3.71) \\
\hline 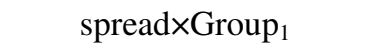 & 0.0240 & (1.94) & 0.0130 & (1.16) \\
\hline${\text { spread } \times \text { Group }_{2}}_{2}$ & 0.0269 & $(2.21)$ & 0.0159 & (1.46) \\
\hline 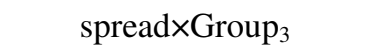 & 0.0271 & (2.09) & 0.0163 & (1.41) \\
\hline${\text { spread } \times \text { Group }_{4}}$ & 0.0291 & $(2.21)$ & 0.0183 & (1.56) \\
\hline${\text { spread } \times \text { Group }_{5}}$ & 0.0297 & $(2.21)$ & 0.0189 & (1.59) \\
\hline${\text { spread } \times \text { Group }_{6}}$ & 0.0239 & (1.71) & 0.0133 & (1.06) \\
\hline${\text { spread } \times \text { Group }_{7}}$ & 0.0148 & (1.10) & 0.0043 & (0.36) \\
\hline spread $\times$ Group $_{8}$ & -0.0082 & $(-0.70)$ & -0.0188 & $(-1.75)$ \\
\hline${\text { spread } \times \text { Group }_{9}}_{9}$ & -0.0421 & $(-3.62)$ & -0.0526 & $(-4.59)$ \\
\hline${\text { spread } \times \text { Group }_{10}}$ & -0.1303 & $(-8.61)$ & -0.1406 & $(-8.85)$ \\
\hline Clustering & \multicolumn{2}{|c|}{ Time } & \multicolumn{2}{|c|}{ Time } \\
\hline $\operatorname{Adj} R^{2}$ & \multicolumn{2}{|c|}{$0.087 \%$} & \multicolumn{2}{|c|}{$0.54 \%$} \\
\hline $\mathrm{N}$ & \multicolumn{2}{|c|}{$6,333,758$} & \multicolumn{2}{|c|}{$6,333,758$} \\
\hline
\end{tabular}

Panel C: The TED spread over the Libor-OIS period

\begin{tabular}{|c|c|c|c|c|}
\hline & \multicolumn{2}{|c|}{ (1) } & \multicolumn{2}{|c|}{ (2) } \\
\hline & estimate & t-stat & estimate & t-stat \\
\hline intercept & 1.0105 & $(218.47)$ & 0.8682 & $(22.55)$ \\
\hline MRKT NORM. SHARE VOL. & -- & -- & 0.1040 & (3.69) \\
\hline${\text { spread } \times \text { Group }_{1}}_{1}$ & 0.0242 & (2.73) & 0.0177 & $(2.21)$ \\
\hline${\text { spread } \times \text { Group }_{2}}$ & 0.0257 & (2.92) & 0.0191 & $(2.43)$ \\
\hline${\operatorname{spread} \times \text { Group }_{3}}$ & 0.0260 & $(2.73)$ & 0.0195 & $(2.30)$ \\
\hline${\text { spread } \times G_{\text {Group }}}_{4}$ & 0.0277 & (2.78) & 0.0212 & (2.38) \\
\hline${\text { spread } \times \text { Group }_{5}}$ & 0.0271 & (2.64) & 0.0208 & $(2.26)$ \\
\hline${\text { spread } \times \text { Group }_{6}}$ & 0.0240 & $(2.25)$ & 0.0177 & (1.85) \\
\hline $\operatorname{spread} \times \mathrm{Group}_{7}$ & 0.0170 & $(1.72)$ & 0.0109 & $(1.22)$ \\
\hline${\text { spread } \times \text { Group }_{8}}$ & 0.0021 & $(0.25)$ & -0.0042 & $(-0.56)$ \\
\hline${\text { spread } \times \text { Group }_{9}}_{9}$ & -0.0265 & $(-3.29)$ & -0.0327 & $(-4.35)$ \\
\hline${\text { spread } \times \text { Group }_{10}}_{10}$ & -0.0931 & $(-10.14)$ & -0.0992 & $(-11.07)$ \\
\hline Clustering & & me & & me \\
\hline Adj $R^{2}$ & & $12 \%$ & & $6 \%$ \\
\hline $\mathrm{N}$ & 6,28 & 6,269 & & 6,269 \\
\hline
\end{tabular}

